\title{
Shotgun proteomics of peach fruit reveals major metabolic pathways associated to ripening
}

\author{
Ricardo Nilo-Poyanco ${ }^{1}$, Carol Moraga ${ }^{2,3}$, Gianfranco Benedetto ${ }^{4}$, Ariel Orellana ${ }^{4,5}$ and \\ Andrea Miyasaka Almeida, ${ }^{6,7^{*}}$
}

\begin{abstract}
Background: Fruit ripening in Prunus persica melting varieties involves several physiological changes that have a direct impact on the fruit organoleptic quality and storage potential. By studying the proteomic differences between the mesocarp of mature and ripe fruit, it would be possible to highlight critical molecular processes involved in the fruit ripening.

Results: To accomplish this goal, the proteome from mature and ripe fruit was assessed from the variety O'Henry through shotgun proteomics using 1D-gel (PAGE-SDS) as fractionation method followed by LC/MS-MS analysis. Data from the 131,435 spectra could be matched to 2740 proteins, using the peach genome reference $v 1$. After data pre-treatment, 1663 proteins could be used for comparison with datasets assessed using transcriptomic approaches and for quantitative protein accumulation analysis. Close to $26 \%$ of the genes that code for the proteins assessed displayed higher expression at ripe fruit compared to other fruit developmental stages, based on published transcriptomic data. Differential accumulation analysis between mature and ripe fruit revealed that 15\% of the proteins identified were modulated by the ripening process, with glycogen and isocitrate metabolism, and protein localization overrepresented in mature fruit, as well as cell wall modification in ripe fruit. Potential biomarkers for the ripening process, due to their differential accumulation and gene expression pattern, included a pectin methylesterase inhibitor, a gibbellerin 2-beta-dioxygenase, an omega-6 fatty acid desaturase, a homeoboxleucine zipper protein and an ACC oxidase. Transcription factors enriched in NAC and Myb protein domains would target preferentially the genes encoding proteins more abundant in mature and ripe fruit, respectively.
\end{abstract}

Conclusions: Shotgun proteomics is an unbiased approach to get deeper into the proteome allowing to detect differences in protein abundance between samples. This technique provided a resolution so that individual gene products could be identified. Many proteins likely involved in cell wall and sugar metabolism, aroma and color, change their abundance during the transition from mature to ripe fruit.

Keywords: Fruit ripening, Proteome, Rosaceae

\footnotetext{
* Correspondence: andrea.miyasaka@umayor.cl

${ }^{6}$ Centro de Genómica y Bioinformática, Facultad de Ciencias, Universidad

Mayor, Camino La Pirámide, 5750 Huechuraba, Chile

${ }^{7}$ Escuela de Agronomía, Facultad de Ciencias, Universidad Mayor, Camino La

Pirámide, 5750 Huechuraba, Chile

Full list of author information is available at the end of the article
}

(c) The Author(s). 2021 Open Access This article is licensed under a Creative Commons Attribution 4.0 International License, which permits use, sharing, adaptation, distribution and reproduction in any medium or format, as long as you give appropriate credit to the original author(s) and the source, provide a link to the Creative Commons licence, and indicate if changes were made. The images or other third party material in this article are included in the article's Creative Commons licence, unless indicated otherwise in a credit line to the material. If material is not included in the article's Creative Commons licence and your intended use is not permitted by statutory regulation or exceeds the permitted use, you will need to obtain permission directly from the copyright holder. To view a copy of this licence, visit http://creativecommons.org/licenses/by/4.0/. The Creative Commons Public Domain Dedication waiver (http://creativecommons.org/publicdomain/zero/1.0/) applies to the data made available in this article, unless otherwise stated in a credit line to the data. 


\section{Background}

Prunus persica (L) Batsch is one of the most economically important fruit crops in the Rosaceae family, with a broad climate distribution, relatively high yield and around 1000 cultivars produced worldwide [1, 2]. P. persica has also become a very important plant model given its compact, small (227.3 Mb) and publicly accessible genome [3], the availability of homozygous doubled haploids, and its taxonomic proximity to other important fruit species such as apricot (P. armeniaca), plum (P. salicina), almond (P. dulcis) and apple (Malus domestica) [4].

Fruit ripening is a complex process that involves changes at multiple biochemical and physiological levels which impacts gene expression [5], proteins and metabolites abundance $[2,6]$. It is the last step of the broader process of fruit development, where the fruit increases in volume and, in some species, the endocarp undergoes a hardening process, enclosing the seed in a secondary lignin-rich cell wall. During ethylene-dependent ripening, fruits transit from a photosynthetically active organ into an organ where the photosynthetic machinery is dismantled, carotenoids, sugars, organic acids and volatile compounds are accumulated, and the cell wall is loosed [7]. Overall, this conversion makes the fruit attractive for consumption as a rich source of fibers, vitamins and antioxidants, as well as its flavor, color and aroma.

Peach fruit ripening has been characterized at the molecular level in processes such as volatile and aroma production [8-10], ethylene and other hormone biosynthesis and signaling [11-13], cell wall dismantling [14], pigments biosynthesis $[15,16]$, and organic acids and sugars metabolism [2, 17-19]. P. persica transcription factors (TFs) involved in anthocyanin induction [16, 20], and ethylene biosynthesis [12, 13, 20] have also been characterized. Transcriptomic studies in $P$. persica have been used to improve the understanding of the molecular processes that underlie fruit chilling injury [21-23], and have not focused on fruit ripening.

Given the above, knowledge is still lacking about how peach fruit ripening is orchestrated at the molecular level. Proteome is a highly dynamic model for understanding the biological processes in an organ. Twodimensional (2D) gels followed by mass spectrometry (MS) analysis have been the most frequent approach to evaluate changes in the proteome of fruits undergoing ripening. However, this approach is limited by the low numbers of proteins of interest identified, co-migration of proteins within the same spot, the absence of hydrophobic proteins, the expertise required to generate high quality $2 \mathrm{D}$-gels and the extended time required to perform the images assessment and statistical analysis [24, 25]. We propose that a $1 \mathrm{D}$-gel followed by LC/MS-MS analysis proteomics approach based on a robust experimental and statistical framework can provide information regarding pathways and biological processes that are crucial for peach fruit ripening. Through this technique we could expand the number of proteins identified during the transition from mature to ripen fruit. The variety selected was O'Henry, since it is a proteome and transcriptome characterized melting peach variety [26, 27], which is the parental to several new-varieties.

\section{Results}

Mature and ripe mesocarp peach fruit proteomes differ greatly between amongst themselves and with other fruit developmental stages

The transition from mature into ripe fruit entails major changes in the fruit mesocarp firmness, titratable acidity, total soluble solids and respiration rate; and more subtle changes in ethylene biosynthesis [28]. Significant change in the respiration rate was detected in ripe fruits $\left(83.4 \mathrm{~mL} \mathrm{CO}_{2} \mathrm{~kg}^{-1} \mathrm{~h}^{-1}\right)$ compared to mature fruit (15.3 mLCO $\left.\mathrm{kg}^{-1} \mathrm{~h}^{-1}\right)$ [28]. Ethylene production in ripe fruits $\left(2.9 \mathrm{~mL} \mathrm{C}_{2} \mathrm{H}_{4} \mathrm{~kg}^{-1}\right.$ $\left.\mathrm{h}^{-1}\right)$ was the double of that measured at harvest (1.7 $\mathrm{mL} \mathrm{C}_{2} \mathrm{H}_{4} \mathrm{~kg}^{-1} \mathrm{~h}^{-1}$ ), suggesting a climacteric stage. This stage is similar to the stage identified as S4II by Pan et al. [29] when ethylene autocatalytic production is increasing. After 6 days of shelf life at $20^{\circ} \mathrm{C}$, the ripe peaches showed a consistent reduction in firmness from around $60 \mathrm{~N}$ to $11 \mathrm{~N}$. Total soluble solids were $11 \%$ at harvest and did not change after ripening [28]. To get a deeper insight into the proteins that are involved in this transition, a 1D SDS-PAGE gel followed by MS analysis was performed (Fig. 1). Data was then analyzed using MASCOT and Scaffold to focus on those proteins identified at a high confidence and to retrieve abundance data from these proteins in a format that is robust for downstream quantitative statistical analysis (Fig. 1, Supplementary Fig. 1). At first, a total of 131,435 spectra could be matched to 2740 proteins, using the peach genome reference v1. After data cleaning from proteins spuriously identified or with an inadequate number of replicates, a total of 1663 proteins were thus included in this study, representing a $6.2 \%$ of the $P$. persica primary transcripts proteome (Supplementary Table 1).

In order to check if the proteome represented by these 1663 proteins had some bias in terms of its physicochemical composition, protein properties such as length, molecular weight, charge, protein stability, and hydrophobicity profiles were compared to the $P$. persica primary transcripts proteome $(26,873$ proteins) and to a similar sized 977 proteins set, extracted from juicy and mealy fruit mesocarp from the Spring Lady variety [30]. In terms of data location, results indicated that for most 


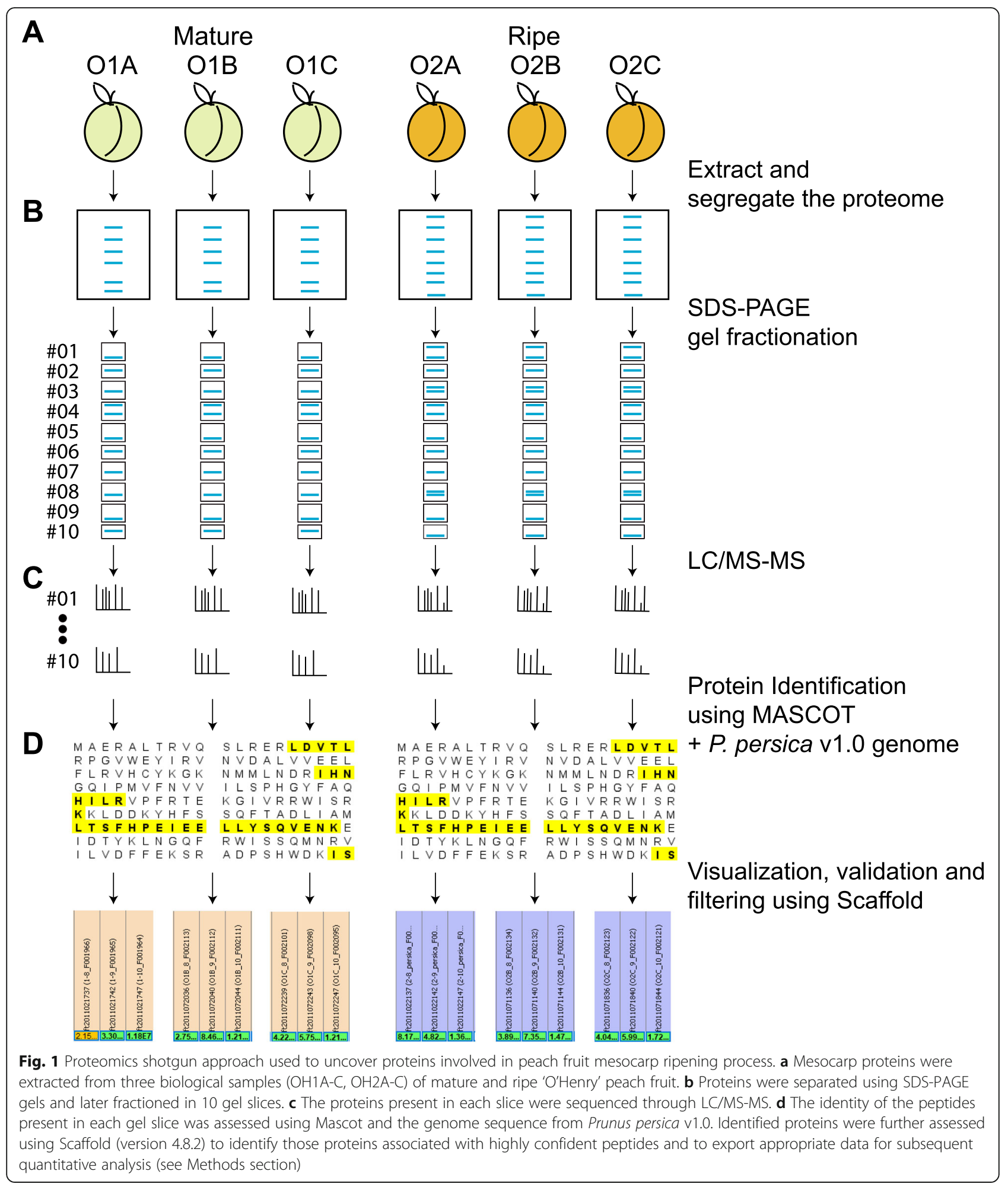

of the parameters selected, the three populations have similar mean values (Supplementary Table 2, Supplementary Fig. 2), with the most substantial differences being related to charge and hydrophobicity, using the Guy scale [31]. In terms of data dispersion, the P. persica primary transcripts proteome displayed a higher dispersion for 5 of the 6 parameters assessed, when compared to the datasets from the current proteome and the proteome from Spring Lady (Supplementary Table 2, Supplementary Fig. 2). 
A single-organism cellular process
sulfur compound metabolic process
carbohydrate derivative metabolic process
proces metabolism

- GO2 - intracellular transport
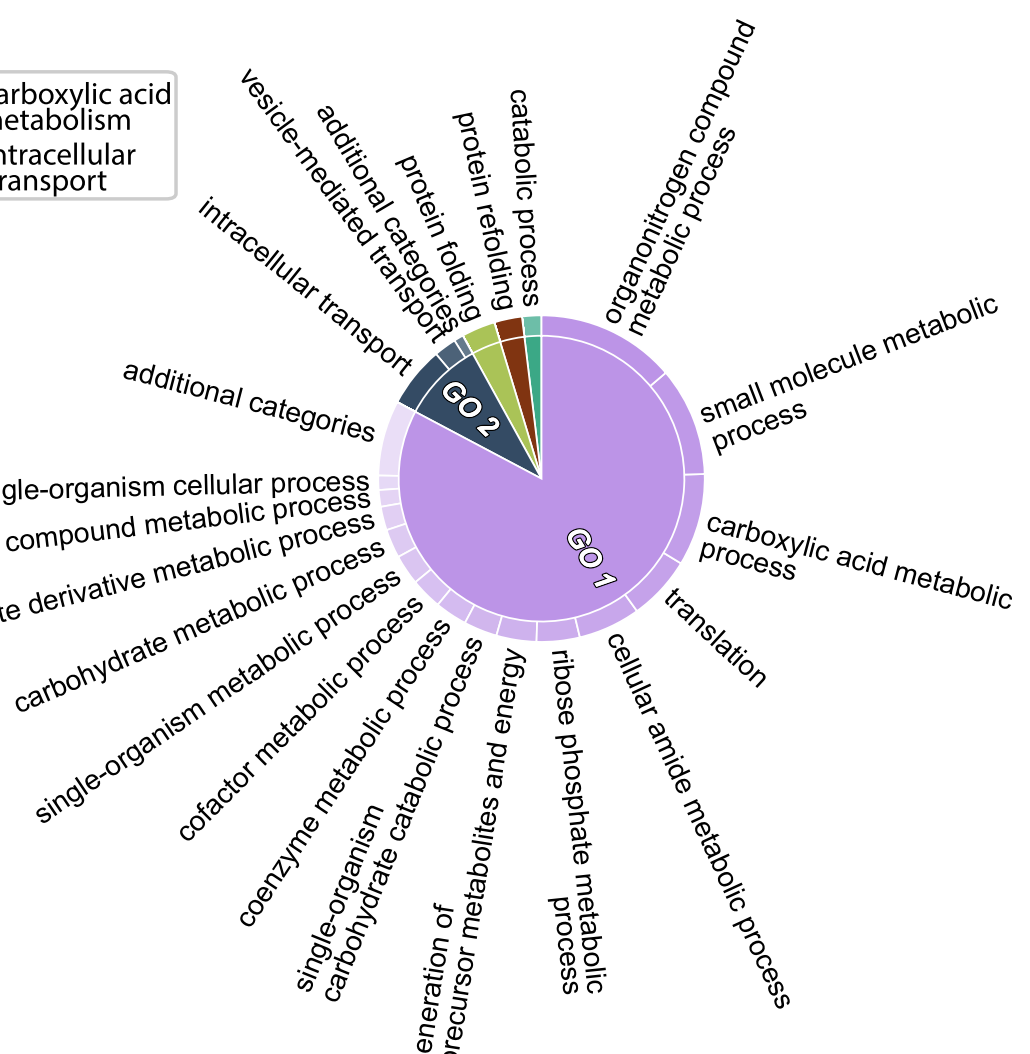

$\begin{array}{llllll}\text { B } & 041 & 054 & 069 & 083 & 111 \mathrm{DAFB}\end{array}$

$\begin{array}{ccccc}\text { vs } & \text { vs } & \text { vs } & \text { vs } & \text { vs } \\ 125 & 125 & 125 & 125 & 125\end{array}$

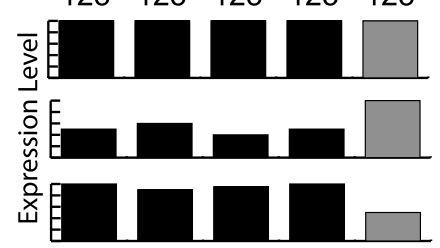

31.7

$-5.9$

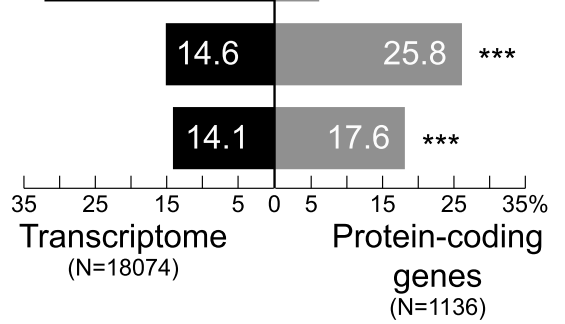

C

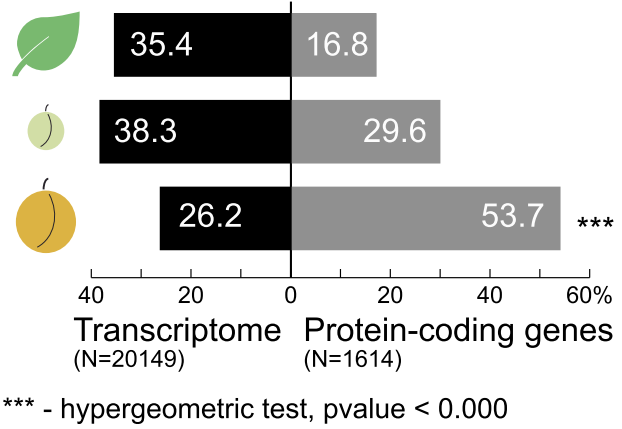

Fig. 2 (See legend on next page.) 
(See figure on previous page.)

Fig. 2 Analysis of global patterns in the proteomics dataset and comparison with related transcriptomic data. a Gene Ontology analysis of the 1163 proteins assessed indicated that this set was enriched in carboxylic acid metabolism, intracellular transport, and to a lesser extent in protein folding. b Expression levels from 18,074 genes from the "Fantasia" variety were assessed at 41, 54, 69, 83, 111 and 125 (ripe fruit) days after full bloom (DAFB). The analysis indicated that $31.7 \%$ of the genes did not display any change when comparing each developmental stage against ripe fruit, $14.6 \%$ displayed its highest level and $14.1 \%$ its lowest level at ripe fruit stage (black bars, first, second and third lane, respectively). When assessing the protein-coding genes detected in mature + ripe fruit (present study), it was estimated that 5.9\% did not display any change when comparing each developmental stage against ripe fruit, $25.8 \%$ displayed its highest level and $17.6 \%$ displayed its lowest level at ripe fruit stage (grey bars, first, second and third lane, respectively). The last two analyses in ripe fruit yielded statistically significant results. c Expression levels from 20,149 genes of the "Babygold" variety were assessed in leaves, immature and ripe fruit. Genes that were more expressed in leaves compared to immature and ripe fruit tissues using the full transcriptome dataset accounted for $35.4 \%$ of the genes (black bars). This number dropped to $16.8 \%$ when using the proteomics dataset (grey bars). The same kind of comparison performed on the genes that were more expressed in the immature and ripe fruit yielded percentages of $38.3 \%$ vs 29.6 and $26.2 \%$ vs $53.7 \%$, being the difference found in ripe fruit statistically significant

The functional analysis of the 1663 proteins identified in this work, performed using Gene Ontology (GO) analysis, indicated that this protein set was enriched in processes related to carboxylic acid metabolism and intracellular transport, and to a lesser extent to protein folding (Fig. 2a).

We next asked if the genes encoding the proteins present in the mesocarp of mature and ripe fruits were more expressed at this stage, or if they were expressed at the same levels in any developmental stage of the fruit development. In order to answer this question, a contrast between the transcriptional expression was performed using 18,074 P. persica genes (herein "fulldataset", variety Fantasia, GEO dataset GSE71561) at 125 days after full bloom (DAFB) against its expression at $41,54,69,83,111$ DAFB. Close to $32 \%$ of the "fulldataset" did not display any expression level difference when contrasting its expression at 125 DAFB, corresponding to mature-ripe fruit stage against any other stage (first lane, dark bar, Fig. 2b). This proportion was $5.9 \%$, when considering the protein-coding genes assessed in this study (1136 genes that matched our dataset, herein "proteomics-dataset", first lane, grey bar, Fig. 2b). When assessing the number of genes that displayed its highest expression levels at 125 DAFB (second lane, Fig. 2b), 14.6\% of the "full-dataset" displayed this behavior, compared to $25.8 \%$ of the "proteomics-dataset." Finally, when assessing the number of genes that displayed its lowest expression levels at 125 DAFB (third lane, Fig. 2b), $14.1 \%$ of the "full-dataset" displayed this behavior, compared to $17.6 \%$ of the "proteomics-dataset". This result indicates that an important proportion of the protein-coding genes characterized in the mesocarp of the mature-ripe fruit reached their highest expression levels at the mature-ripe stage of the peach fruit developmental curve.

Similar to the previous analysis, we evaluated if the protein-coding genes expressed at the fruit mesocarp during the fruit ripening were mainly expressed at this tissue or if they had an even expression across leaves, immature and ripe fruit. Therefore, a transcriptomic dataset derived from the variety Babygold, consisting of 20,149 genes, whose expression was characterized by means of RNA-seq at leaves, $2 \mathrm{~cm}$ immature and ripe fruit mesocarp (Fig. 2c) [32], was assessed. Gene expression at leaves was characterized by $35.4 \%$ of the genes being more expressed at this tissue, compared to $16.8 \%$ in the current "proteomics-dataset." Gene expression in immature fruit displayed $38.3 \%$ of the genes being more expressed at this tissue, whereas in the "proteomicsdataset" this number was of $29.6 \%$. Finally, at ripe fruit, $26.2 \%$ of the genes displayed a higher expression in this tissue, whereas in the "proteomics-dataset" this number doubled to $53.7 \%$. This result indicates that half of the protein-coding genes characterized in the mesocarp of the mature-ripe fruit reached their highest expression at this stage.

\section{Proteomic differences between mature and ripe fruits} points to the mature fruit as the main stage in which sugar metabolism is modulated in the fruit mesocarp Principal component analysis (PCA) was used as a diagnostic plot and to identify the main variables that explain the proteomic differences between the samples assessed. PCA was performed using the 1663 proteins identified in all mature $(\mathrm{O} 1)$ and ripe $(\mathrm{O} 2)$ fruit samples assessed in this study. The principal component 1 (PC1) segregates mature from ripe fruit, explaining $33.8 \%$ of the variance associated to the samples, a high value considering that the samples used were biological replicates harvested from field grown trees (Fig. 3A). In fact, the second component could explain $23.2 \%$ of the variability and was likely associated with differences among fruits.

Quantitative changes between mature and ripe fruit proteome were assessed using a t-test after centering, normalizing and scaling the data to achieve a close to normal distribution (Methods section, Supplementary Fig. 1). Mature and ripe fruit displayed 52 and 22 proteins with an exclusive presence (referred as "Only pres.") in each stage respectively, and 88 and 86 proteins 


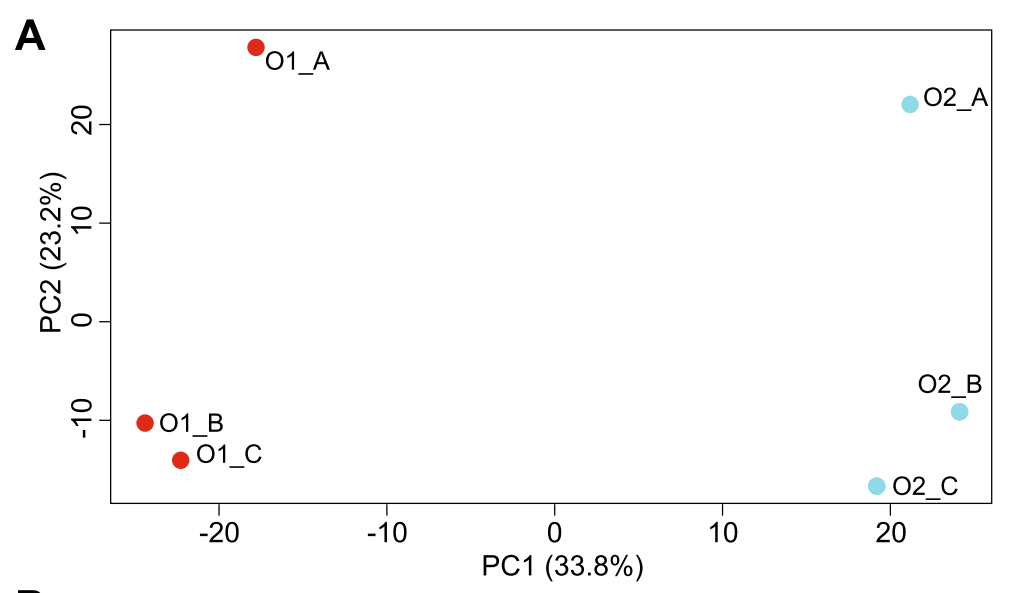

B
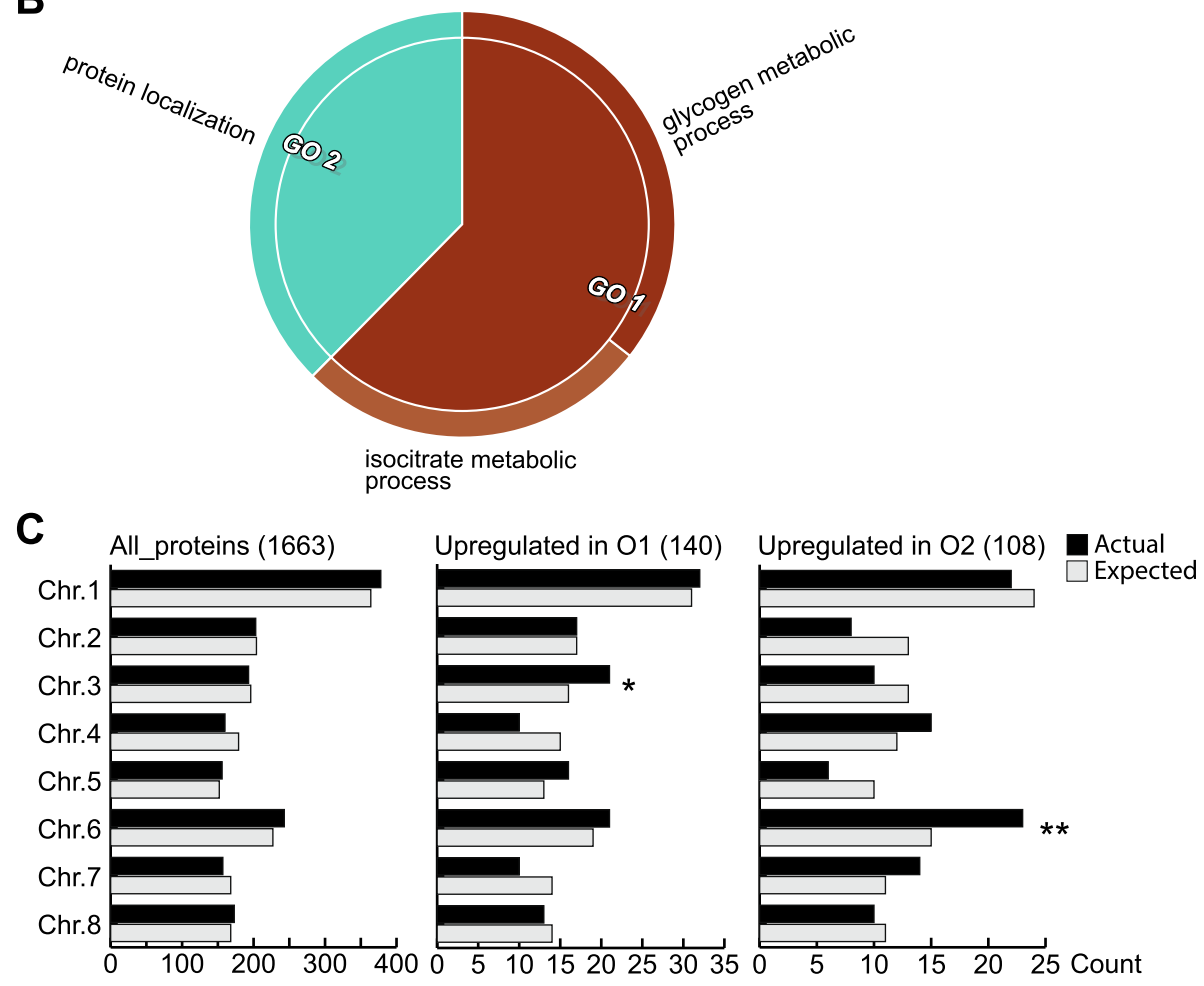

Fig. 3 Analysis of proteins differentially accumulated in mature and ripe fruit. a All 1663 proteins detected in mature $(\mathrm{O} 1)$ and ripe $(\mathrm{O} 2)$ fruit were used to perform a Principal Component Analysis (PCA), with PC1 segregating mature from ripe fruit (A). From these 1663 proteins, 248 displayed a differential accumulation in $\mathrm{O} 1$ and $\mathrm{O} 2$ samples. $\mathbf{b}$ The main biological processes related to the differentially accumulated proteins in $\mathrm{O} 1 \mathrm{fruit}$ were associated to glycogen and isocitrate metabolism, and protein localization. c When assessing all the 1663 characterized proteins ("All_proteins"), no enrichment was found. Among the proteins upregulated in mature fruit, those with protein-coding genes in chromosome 3 (actual, black bars) were more than expected by chance (expected, grey bars, hypergeometric test, pvalue < 0.05). The same analysis determined that those protein-coding genes upregulated in ripe fruit were located, more than expected by chance, in chromosome 6 (pvalue $<0.01$ ). Chr. - Chromosome

with a significative change in abundance during the mature to ripe transition, respectively. Overall, 248 (14.9\%) of the proteins identified in this study displayed a differential abundance between mature and ripe fruit (Table 1). A functional enrichment analysis of the proteins with a differential abundance was performed using Gene Ontology (GO). Proteins more abundant in mature fruit were associated to glycogen and isocitrate metabolism, and protein localization (Fig. 3B). No enrichment in any of the three GO sub-ontologies was found for proteins more abundant in ripe fruit. In terms of the chromosome distribution of the gene coding for these differentially accumulated proteins, the set differentially accumulated in mature fruit was enriched in 
Table 1 Proteins differentially accumulated and with functional assignment

\begin{tabular}{|c|c|c|c|c|c|c|c|}
\hline Process & Prupe_ID & $\begin{array}{l}\text { Protein } \\
\text { identification } \\
\text { probability }\end{array}$ & $\begin{array}{l}\text { Exclusive unique } \\
\text { peptide count }\end{array}$ & DA_class ${ }^{a}$ & Annotation & $\begin{array}{l}\text { Best } A . \\
\text { thaliana } \\
\text { Match }\end{array}$ & $\begin{array}{l}\text { Possibly } \\
\text { Related to } \\
\text { Volatiles } \\
\text { Metabolism }^{\mathbf{b}} \\
\end{array}$ \\
\hline \multicolumn{8}{|l|}{ Upregulated 01} \\
\hline \multirow[t]{4}{*}{ Abiotic Stress } & Prupe.4G138700 & 0.997 & 1 & Up_O1 & Elongation factor 2 & AT1G56070 & \\
\hline & Prupe.6G353600 & 0.154 & 0 & Up_O1 & Translational activator GCN1 & AT1G64790 & \\
\hline & Prupe.3G043000 & 0.998 & 2 & Up_O1 & $\begin{array}{l}\text { Developmentally-regulated G- } \\
\text { protein } 2\end{array}$ & AT1G72660 & \\
\hline & Prupe.5G098100 & 0.643 & 1 & Up_O1 & Glutathione S-transferase T1 & AT5G41210 & \\
\hline $\begin{array}{l}\text { Actin } \\
\text { Organization/ } \\
\text { Signaling }\end{array}$ & Prupe.6G320500 & 0.995 & 1 & Up_O1 & $\begin{array}{l}\text { capping protein (actin } \\
\text { filament) muscle Z-line, alpha } \\
\text { (CAPZA) }\end{array}$ & AT3G05520 & \\
\hline \multirow[t]{5}{*}{$\begin{array}{l}\text { Amino Acids } \\
\text { Metabolism }\end{array}$} & Prupe.7G039100 & 0.366 & 0 & Qualit_O1 & $\begin{array}{l}\text { Glutamate synthase } \\
\text { (ferredoxin) / Ferredoxin- } \\
\text { dependent glutamate } \\
\text { synthase }\end{array}$ & AT5G04140 & \\
\hline & Prupe.5G056900 & 1 & 2 & Qualit_01 & Glutamate dehydrogenase 2 & AT5G07440 & \\
\hline & Prupe.5G171400 & 0.998 & 2 & Up_O1 & $\begin{array}{l}\text { Anthranilate } \\
\text { phosphoribosyltransferase / } \\
\text { Phosphoribosyl-anthranilate } \\
\text { pyrophosphorylase }\end{array}$ & AT5G17990 & \\
\hline & Prupe.6G249100 & 0.999 & 1 & Up_O1 & $\begin{array}{l}\text { Diaminopimelate epimerase, } \\
\text { chloroplastic }\end{array}$ & AT3G53580 & \\
\hline & Prupe.8G013600 & 1 & 2 & Up_O1 & $\begin{array}{l}\text { ATP phosphoribosyltransferase } \\
\text { / Phosphoribosyl-ATP } \\
\text { pyrophosphorylase }\end{array}$ & AT1G09795 & \\
\hline \multirow{3}{*}{$\begin{array}{l}\text { Carbohydrate } \\
\text { Metabolism/ } \\
\text { Abiotic Stress } \\
\text { Response }\end{array}$} & Prupe.3G289900 & 1 & 2 & Qualit_O1 & $\begin{array}{l}\text { GALACTINOL--SUCROSE } \\
\text { GALACTOSYLTRANSFERASE 5- } \\
\text { RELATED }\end{array}$ & AT5G40390 & \\
\hline & Prupe.7G248600 & 1 & 13 & Qualit_O1 & $\begin{array}{l}\text { GALACTINOL--SUCROSE } \\
\text { GALACTOSYLTRANSFERASE 6- } \\
\text { RELATED }\end{array}$ & AT5G20250 & \\
\hline & Prupe.6G032400 & 0.115 & 0 & Up_O1 & $\begin{array}{l}\text { Galactinol--sucrose } \\
\text { galactosyltransferase / } \\
\text { Raffinose synthase }\end{array}$ & AT1G55740 & \\
\hline \multirow[t]{6}{*}{$\begin{array}{l}\text { Carbohydrates } \\
\text { Metabolism }\end{array}$} & Prupe.3G192600 & 1 & 7 & Qualit_O1 & $\begin{array}{l}\text { GLUCOSE-1-PHOSPHATE } \\
\text { ADENYLYLTRANSFERASE } \\
\text { SMALL SUBUNIT, } \\
\text { CHLOROPLASTIC }\end{array}$ & AT5G48300 & \\
\hline & Prupe.6G076300 & 1 & 3 & Qualit_01 & $\begin{array}{l}\text { Triose-phosphate isomerase / } \\
\text { Triosephosphate mutase }\end{array}$ & AT3G55440 & \\
\hline & Prupe.1G196700 & 1 & 5 & Qualit_O1 & Probable fructokinase-2 & AT1G06030 & \\
\hline & Prupe.1G354000 & 1 & 2 & Qualit_O1 & $\begin{array}{l}\text { 1,4-alpha-glucan-branching } \\
\text { enzyme 1, chloroplastic/ } \\
\text { amyloplastic }\end{array}$ & AT5G03650 & \\
\hline & Prupe.1G376200 & 1 & 6 & Up_O1 & $\begin{array}{l}\text { GLUCOSE-1-PHOSPHATE } \\
\text { ADENYLYLTRANSFERASE } \\
\text { LARGE SUBUNIT 2, } \\
\text { CHLOROPLASTIC }\end{array}$ & AT1G27680 & \\
\hline & Prupe.1G378500 & 0.998 & 2 & Up_O1 & $\begin{array}{l}\text { SUGAR TRANSPORTER ERD6- } \\
\text { LIKE 4-RELATED }\end{array}$ & AT1G75220 & \\
\hline \multirow{2}{*}{$\begin{array}{l}\text { Carbohydrates/ } \\
\text { Energy } \\
\text { Metabolism }\end{array}$} & Prupe.4G124500 & 0.998 & 2 & Qualit_O1 & $\begin{array}{l}\text { Isocitrate dehydrogenase } \\
\text { [NADP] }\end{array}$ & AT1G54340 & \\
\hline & Prupe.3G288200 & 0.15 & 0 & Up_O1 & $\begin{array}{l}\text { ISOCITRATE DEHYDROGENASE } \\
\text { [NADP], CHLOROPLASTIC/ } \\
\text { MITOCHONDRIAL }\end{array}$ & AT5G14590 & \\
\hline
\end{tabular}


Table 1 Proteins differentially accumulated and with functional assignment (Continued)

\begin{tabular}{|c|c|c|c|c|c|c|c|}
\hline Process & Prupe_ID & $\begin{array}{l}\text { Protein } \\
\text { identification } \\
\text { probability }\end{array}$ & $\begin{array}{l}\text { Exclusive unique } \\
\text { peptide count }\end{array}$ & DA_class ${ }^{a}$ & Annotation & $\begin{array}{l}\text { Best } A \text {. } \\
\text { thaliana } \\
\text { Match }\end{array}$ & $\begin{array}{l}\text { Possibly } \\
\text { Related to } \\
\text { Volatiles } \\
\text { Metabolism }\end{array}$ \\
\hline $\begin{array}{l}\text { Carbohydrates } \\
\text { Metabolism/Redox } \\
\text { Metabolism }\end{array}$ & Prupe.2G091600 & 0.5 & 1 & Up_O1 & $\begin{array}{l}\text { Malate dehydrogenase } \\
(\mathrm{NADP}(+)) \text { / NADP-linked } \\
\text { malate dehydrogenase }\end{array}$ & AT5G58330 & \\
\hline $\begin{array}{l}\text { Carbohydrates } \\
\text { Metabolism/ } \\
\text { Signaling }\end{array}$ & Prupe.4G1 10600 & 0.995 & 1 & Up_O1 & $\begin{array}{l}\text { Phosphatase IMPL1, } \\
\text { chloroplastic }\end{array}$ & AT1G31190 & \\
\hline Cell Division & Prupe.8G209400 & 0.283 & 0 & Up_O1 & CLIP-associated protein & AT2G20190 & \\
\hline \multirow[t]{2}{*}{$\begin{array}{l}\text { Cell Wall } \\
\text { Metabolism }\end{array}$} & Prupe.5G123800 & 0.998 & 2 & Qualit_O1 & $\begin{array}{l}\text { CELLULOSE SYNTHASE-LIKE } \\
\text { PROTEIN G1-RELATED }\end{array}$ & AT4G23990 & \\
\hline & Prupe.5G118000 & 0.999 & 2 & Qualit_O1 & $\begin{array}{l}\text { ENDOGLUCANASE 19- } \\
\text { RELATED }\end{array}$ & AT1G64390 & \\
\hline $\begin{array}{l}\text { Cell Wall } \\
\text { Metabolism/ } \\
\text { Signaling }\end{array}$ & Prupe.7G266700 & 0.122 & 0 & Qualit_O1 & $\begin{array}{l}\text { Probable phosphoinositide } \\
\text { phosphatase SAC9 }\end{array}$ & AT3G59770 & \\
\hline $\begin{array}{l}\text { Cellular Response } \\
\text { to Light Intensity }\end{array}$ & Prupe.3G235100 & 0.998 & 2 & Up_O1 & $\begin{array}{l}\text { Photosystem II repair protein } \\
\text { PSB27-H1, chloroplastic }\end{array}$ & AT1G03600 & \\
\hline $\begin{array}{l}\text { Cellular Response } \\
\text { to Light Intensity/ } \\
\text { Abiotic Stress } \\
\text { Response }\end{array}$ & Prupe.1G264900 & 0.998 & 2 & Qualit_O1 & Glutathione S-transferase & AT1G10370 & \\
\hline \multirow{2}{*}{$\begin{array}{l}\text { Chloroplast } \\
\text { Photorelocation } \\
\text { Movements }\end{array}$} & Prupe.1G498000 & 1 & 3 & Up_O1 & $\begin{array}{l}\text { PLASTID MOVEMENT } \\
\text { IMPAIRED1 }\end{array}$ & AT1G42550 & \\
\hline & Prupe.1G263000 & 1 & 2 & Up_O1 & protein phosphatase $2 \mathrm{~A}-2$ & AT1G10430 & \\
\hline $\begin{array}{l}\text { Chloroplast } \\
\text { protein import }\end{array}$ & Prupe.1G170300 & 1 & 3 & Up_O1 & $\begin{array}{l}\text { Protein TIC 22-like, } \\
\text { chloroplastic }\end{array}$ & AT3G23710 & \\
\hline $\begin{array}{l}\text { Cofactor (Vit E) } \\
\text { Metabolism }\end{array}$ & Prupe.1G023700 & 0.074 & 0 & Up_O1 & $\begin{array}{l}\text { 2-methyl-6-phytyl-1,4- } \\
\text { hydroquinone } \\
\text { methyltransferase, } \\
\text { chloroplastic }\end{array}$ & AT3G63410 & \\
\hline $\begin{array}{l}\text { Cytoskeleton } \\
\text { Organization }\end{array}$ & Prupe.7G059400 & 0.479 & 0 & Up_O1 & Villin-2 & AT2G41740 & \\
\hline Detoxification & Prupe.4G243800 & 0.998 & 2 & Qualit_O1 & $\begin{array}{l}\text { ADP-ribose diphosphatase / } \\
\text { ADPR-PPase // NAD(+) } \\
\text { diphosphatase }\end{array}$ & AT4G25434 & \\
\hline \multirow[t]{4}{*}{$\begin{array}{l}\text { Energy } \\
\text { Metabolism }\end{array}$} & Prupe.2G325400 & 1 & 2 & Qualit_O1 & $\begin{array}{l}\text { Probable NADH } \\
\text { dehydrogenase [ubiquinone] } \\
1 \text { alpha subcomplex subunit } \\
12\end{array}$ & AT3G03100 & \\
\hline & Prupe.1G231900 & 1 & 3 & Up_O1 & $\begin{array}{l}\text { NADH dehydrogenase } \\
\text { (ubiquinone) flavoprotein } 1 \\
\text { (NDUFV1) }\end{array}$ & AT5G08530 & \\
\hline & Prupe.2G281900 & 0.998 & 2 & Up_O1 & ENOLASE & AT2G36530 & \\
\hline & Prupe.3G056600 & 1 & 10 & Up_O1 & $\begin{array}{l}\text { 6-PHOSPHOFRUCTOKINASE 1- } \\
\text { RELATED }\end{array}$ & AT4G26270 & \\
\hline \multirow[t]{2}{*}{ Esters Catabolism } & Prupe.1G439300 & 0.998 & 2 & Up_O1 & $\begin{array}{l}\text { CARBOXYLESTERASE 2- } \\
\text { RELATED }\end{array}$ & AT1G47480 & \\
\hline & Prupe.8G121500 & 0.976 & 1 & Up_O1 & $\begin{array}{l}\text { CARBOXYLESTERASE 12- } \\
\text { RELATED }\end{array}$ & AT3G48700 & \\
\hline \multirow{3}{*}{$\begin{array}{l}\text { Hormones } \\
\text { Metabolism/ } \\
\text { Signaling }\end{array}$} & Prupe.6G295900 & 0.217 & 0 & Up_O1 & $\begin{array}{l}\text { RECEPTOR-LIKE PROTEIN } \\
\text { KINASE FERONIA }\end{array}$ & AT3G51550 & \\
\hline & Prupe.6G065600 & 1 & 7 & Up_O1 & BR-signaling kinase (BSK) & AT5G59010 & \\
\hline & Prupe.8G250300 & 0.5 & 1 & Up_O1 & $\begin{array}{l}\text { BRI1 suppressor } 1 \text { (BSU1)-like } \\
1\end{array}$ & AT4G03080 & \\
\hline
\end{tabular}


Table 1 Proteins differentially accumulated and with functional assignment (Continued)

\begin{tabular}{|c|c|c|c|c|c|c|c|}
\hline Process & Prupe_ID & $\begin{array}{l}\text { Protein } \\
\text { identification } \\
\text { probability }\end{array}$ & $\begin{array}{l}\text { Exclusive unique } \\
\text { peptide count }\end{array}$ & DA_class ${ }^{a}$ & Annotation & $\begin{array}{l}\text { Best } A \text {. } \\
\text { thaliana } \\
\text { Match }\end{array}$ & $\begin{array}{l}\text { Possibly } \\
\text { Related to } \\
\text { Volatiles } \\
\text { Metabolism }\end{array}$ \\
\hline $\begin{array}{l}\text { Lactones } \\
\text { Biosynthesis }\end{array}$ & Prupe.7G162300 & 0.998 & 2 & Up_O1 & $\begin{array}{l}\text { 3-hydroxyacyl-CoA } \\
\text { dehydrogenase }\end{array}$ & AT3G51000 & YES \\
\hline \multirow[t]{8}{*}{ Lipids Metabolism } & Prupe.4G132600 & 0.994 & 1 & Qualit_O1 & $\begin{array}{l}\text { 2,4-dienoyl-CoA reductase } \\
\text { (NADPH) / 4-enoyl-CoA } \\
\text { reductase (NADPH) }\end{array}$ & AT3G12800 & \\
\hline & Prupe.7G175400 & 0.989 & 0 & Qualit_O1 & PHOSPHOLIPASE D DELTA & AT4G35790 & \\
\hline & Prupe.8G162500 & 0.5 & 1 & Up_O1 & $\begin{array}{l}\text { Phosphatidylinositol } \\
\text { diacylglycerol-lyase / } \\
\text { Phosphatidylinositol } \\
\text { phospholipase C }\end{array}$ & AT4G38690 & \\
\hline & Prupe.3G064800 & 1 & 3 & Qualit_O1 & $\begin{array}{l}\text { Peroxyureidoacrylate/ } \\
\text { ureidoacrylate } \\
\text { amidohydrolase }\end{array}$ & AT3G16190 & \\
\hline & Prupe.6G180800 & 0.985 & 1 & Up_O1 & $\begin{array}{l}\text { 3-hydroxyacyl-[acyl-carrier- } \\
\text { protein] dehydratase / D-3- } \\
\text { hydroxyoctanoyl-[acyl carrier } \\
\text { protein] dehydratase }\end{array}$ & AT5G10160 & \\
\hline & Prupe.5G079200 & 0.998 & 2 & Qualit_O1 & ACID CLUSTER PROTEIN 33 & AT4G12230 & YES \\
\hline & Prupe.1G512000 & 0.104 & 0 & Up_O1 & Acetyl-CoA carboxylase 1 & AT1G36160 & \\
\hline & Prupe.3G176900 & 1 & 3 & Qualit_O1 & $\begin{array}{l}\text { 3-hydroxyisobutyryl-CoA } \\
\text { hydrolase-like protein } 5\end{array}$ & AT1G06550 & \\
\hline $\begin{array}{l}\text { Lipids/Redox } \\
\text { Metabolism }\end{array}$ & Prupe.6G063600 & 1 & 5 & Up_O1 & neutral ceramidase (ASAH2) & AT1G07380 & \\
\hline \multirow[t]{3}{*}{$\begin{array}{l}\text { Microtubules } \\
\text { Organization }\end{array}$} & Prupe.6G088500 & 0.083 & 0 & Qualit_O1 & $\begin{array}{l}\text { KINESIN MOTOR PROTEIN- } \\
\text { RELATED PROTEIN-RELATED }\end{array}$ & AT3G45850 & \\
\hline & Prupe.1G083500 & 0.236 & 0 & Up_O1 & Protein MOR1 & AT2G35630 & \\
\hline & Prupe.5G206800 & 0.998 & 2 & Up_O1 & PROTEIN SPIRAL1 & AT1G26355 & \\
\hline \multirow[t]{2}{*}{$\begin{array}{l}\text { Organelles } \\
\text { Morphogenesis }\end{array}$} & Prupe.3G172600 & 1 & 2 & Qualit_01 & $\begin{array}{l}\text { peroxisomal and } \\
\text { mitochondrial division factor } 2\end{array}$ & AT1G06530 & \\
\hline & Prupe.6G326600 & 1 & 4 & Up_O1 & $\begin{array}{l}\text { Ras homolog gene family, } \\
\text { member T1 (RHOT1, ARHT1) }\end{array}$ & AT5G27540 & \\
\hline $\begin{array}{l}\text { Nucleosides and } \\
\text { Nucleotides } \\
\text { Biosynthesis }\end{array}$ & Prupe.3G304300 & 1 & 3 & Up_O1 & URIDINE KINASE & AT5G40870 & \\
\hline $\begin{array}{l}\text { Peroxisome } \\
\text { organization }\end{array}$ & Prupe.3G220500 & 0.5 & 1 & Qualit_01 & $\begin{array}{l}\text { Peroxisome biogenesis } \\
\text { protein }\end{array}$ & AT3G21865 & \\
\hline \multirow{3}{*}{$\begin{array}{l}\text { Phenylpropanoids } \\
\text { Metabolism }\end{array}$} & Prupe.2G319700 & 1 & 5 & Qualit_01 & Caffeate O-methyltransferase & AT5G54160 & \\
\hline & Prupe.2G263900 & 1 & 4 & Qualit_O1 & $\begin{array}{l}\text { CHALCONE--FLAVONONE } \\
\text { ISOMERASE 3-RELATED }\end{array}$ & AT5G05270 & \\
\hline & Prupe.3G194000 & 1 & 2 & Qualit_O1 & $\begin{array}{l}\text { Cinnamyl alcohol } \\
\text { dehydrogenase }\end{array}$ & AT1G72680 & \\
\hline $\begin{array}{l}\text { Photoperiodic } \\
\text { Flowering } \\
\text { Regulation }\end{array}$ & Prupe.6G149500 & 0.614 & 1 & Qualit_01 & $\begin{array}{l}\text { Ubiquitin carboxyl-terminal } \\
\text { hydrolase } 12\end{array}$ & AT5G06600 & \\
\hline \multirow{2}{*}{$\begin{array}{l}\text { Polyamines } \\
\text { metabolism }\end{array}$} & Prupe.5G078900 & 0.977 & 1 & Qualit_O1 & AMINE OXIDASE-RELATED & AT4G12290 & \\
\hline & Prupe.1G255300 & 0.5 & 1 & Up_O1 & $\begin{array}{l}\text { spermidine synthase (speE, } \\
\text { SRM) }\end{array}$ & AT1G23820 & \\
\hline $\begin{array}{l}\text { Processing of } \\
\text { Vacuolar Seed } \\
\text { Protein Precursors }\end{array}$ & Prupe.5G076300 & 0.998 & 2 & Up_O1 & $\begin{array}{l}\text { HEMOGLOBINASE FAMILY } \\
\text { MEMBER }\end{array}$ & AT1G62710 & \\
\hline $\begin{array}{l}\text { Protein } \\
\text { Degradation }\end{array}$ & Prupe.8G251000 & 0.998 & 1 & Qualit_O1 & $\begin{array}{l}\text { nuclear protein localization } \\
\text { protein } 4 \text { homolog (NPLOC4, }\end{array}$ & AT2G47970 & \\
\hline
\end{tabular}


Table 1 Proteins differentially accumulated and with functional assignment (Continued)

\begin{tabular}{|c|c|c|c|c|c|c|c|}
\hline Process & Prupe_ID & $\begin{array}{l}\text { Protein } \\
\text { identification } \\
\text { probability }\end{array}$ & $\begin{array}{l}\text { Exclusive unique } \\
\text { peptide count }\end{array}$ & DA_class ${ }^{a}$ & Annotation & $\begin{array}{l}\text { Best } A \text {. } \\
\text { thaliana } \\
\text { Match }\end{array}$ & $\begin{array}{l}\text { Possibly } \\
\text { Related to } \\
\text { Volatiles } \\
\text { Metabolism }^{\text {b }} \\
\end{array}$ \\
\hline & & & & & NPL4) & & \\
\hline Protein Folding & Prupe.8G161100 & 1 & 9 & Up_O1 & $\begin{array}{l}\text { PEPTIDYL-PROLYL CIS-TRANS } \\
\text { ISOMERASE }\end{array}$ & AT2G16600 & \\
\hline $\begin{array}{l}\text { Protein } \\
\text { Modification }\end{array}$ & Prupe.2G212600 & 0.621 & 1 & Up_O1 & $\begin{array}{l}\text { oligosaccharyltransferase } \\
\text { complex subunit alpha } \\
\text { (ribophorin I) (OST1, RPN1) }\end{array}$ & AT2G01720 & \\
\hline \multirow[t]{5}{*}{ Protein Synthesis } & Prupe.1G133900 & 1 & 6 & Qualit_O1 & $\begin{array}{l}\text { Eukaryotic translation } \\
\text { initiation factor } 2 \text { subunit } 3\end{array}$ & AT1G04170 & \\
\hline & Prupe.1G177100 & 0.999 & 2 & Qualit_O1 & $\begin{array}{l}\text { Eukaryotic translation } \\
\text { initiation factor } 3 \text { subunit H }\end{array}$ & AT1G10840 & \\
\hline & Prupe.3G187100 & 1 & 5 & Up_O1 & 605 ribosomal protein $L 27-3$ & AT4G15000 & \\
\hline & Prupe.3G286600 & 0.998 & 2 & Up_O1 & $\begin{array}{l}\text { Large subunit ribosomal } \\
\text { protein } \mathrm{L} 7 / \mathrm{L} 12 \text { (RP-L7, } \\
\text { MRPL12, rplL) }\end{array}$ & AT3G27830 & \\
\hline & Prupe.7G052700 & 1 & 7 & Up_O1 & $\begin{array}{l}\text { Eukaryotic translation } \\
\text { initiation factor } 3 \text { subunit E }\end{array}$ & AT3G57290 & \\
\hline Protein Targeting & Prupe.3G089600 & 1 & 1 & Up_O1 & $\begin{array}{l}\text { SIGNAL RECOGNITION } \\
\text { PARTICLE } 54 \text { KDA PROTEIN }\end{array}$ & AT1G48900 & \\
\hline $\begin{array}{l}\text { Pyrophosphate } \\
\text { Metabolism and } \\
\text { Photosynthate } \\
\text { Partitioning }\end{array}$ & Prupe.3G091900 & 0.998 & 1 & Qualit_O1 & $\begin{array}{l}\text { Inorganic pyrophosphatase } \\
\text { (ppa) }\end{array}$ & AT1G15690 & \\
\hline Redox Metabolism & Prupe.2G051700 & 1 & 3 & Qualit_O1 & RING FINGER PROTEIN 41, 151 & AT3G54360 & \\
\hline $\begin{array}{l}\text { Regulation of L- } \\
\text { ascorbic acid } \\
\text { Biosynthetic } \\
\text { Process }\end{array}$ & Prupe.5G179900 & 0.998 & 2 & Qualit_O1 & $\begin{array}{l}\text { Mannose-1-phosphate } \\
\text { guanyltransferase alpha }\end{array}$ & AT1G74910 & \\
\hline $\begin{array}{l}\text { Regulation of } \\
\text { Plant Cytokinesis/ } \\
\text { Abiotic Stress } \\
\text { Response }\end{array}$ & Prupe.5G105500 & 0.997 & 1 & Up_O1 & $\begin{array}{l}\text { MITOGEN-ACTIVATED } \\
\text { PROTEIN KINASE } 5\end{array}$ & AT4G01370 & \\
\hline $\begin{array}{l}\text { Regulation of } \\
\text { Translation }\end{array}$ & Prupe.6G154800 & 0.054 & 0 & Qualit_O1 & Protein argonaute 4 & AT2G27040 & \\
\hline RNA biogenesis & Prupe.2G121400 & 0.998 & 2 & Up_O1 & $\begin{array}{l}\text { DNA-directed RNA } \\
\text { polymerases II and IV subunit } \\
5 \text { A }\end{array}$ & AT3G22320 & \\
\hline $\begin{array}{l}\text { RNA biogenesis/ } \\
\text { Abiotic Stress } \\
\text { Response }\end{array}$ & Prupe.1G346100 & 1 & 3 & Qualit_O1 & $\begin{array}{l}\text { ATP-dependent RNA helicase } \\
\text { (EIF4A3, FAL1) }\end{array}$ & AT3G19760 & \\
\hline \multirow[t]{2}{*}{ RNA Splicing } & Prupe.3G036300 & 0.135 & 0 & Qualit_01 & $\begin{array}{l}116 \mathrm{kDa} \text { U5 small nuclear } \\
\text { ribonucleoprotein component } \\
\text { (EFTUD2) }\end{array}$ & AT1G06220 & \\
\hline & Prupe.2G275100 & 0.564 & 0 & Up_O1 & SPLICING FACTOR 1 & AT5G51300 & \\
\hline $\begin{array}{l}\text { Scaffolds in } \\
\text { Cellular Signaling } \\
\text { and Trafficking }\end{array}$ & Prupe.5G125200 & 0.772 & 1 & Qualit_O1 & KINESIN LIGHT CHAIN & AT4G10840 & \\
\hline Solute Transport & Prupe.1G460700 & 0.563 & 1 & Qualit_01 & Plasma membrane ATPase 4 & AT2G24520 & \\
\hline \multirow[t]{3}{*}{$\begin{array}{l}\text { Specialized } \\
\text { Metabolsim }\end{array}$} & Prupe.6G325100 & 1 & 4 & Up_O1 & $\begin{array}{l}\text { Aryldialkylphosphatase / } \\
\text { Phosphotriesterase }\end{array}$ & AT3G05350 & YES \\
\hline & Prupe.3G026100 & 1 & 2 & Up_O1 & $\begin{array}{l}\text { Cycloartenol synthase / 2,3- } \\
\text { epoxysqualene--cycloartenol } \\
\text { cyclase }\end{array}$ & AT2G07050 & \\
\hline & Prupe.4G002700 & 1 & 2 & Up_O1 & Farnesyl pyrophosphate & AT5G47770 & \\
\hline
\end{tabular}


Table 1 Proteins differentially accumulated and with functional assignment (Continued)

\begin{tabular}{|c|c|c|c|c|c|c|c|}
\hline Process & Prupe_ID & $\begin{array}{l}\text { Protein } \\
\text { identification } \\
\text { probability }\end{array}$ & $\begin{array}{l}\text { Exclusive unique } \\
\text { peptide count }\end{array}$ & DA_class ${ }^{a}$ & Annotation & $\begin{array}{l}\text { Best } A \text {. } \\
\text { thaliana } \\
\text { Match }\end{array}$ & $\begin{array}{l}\text { Possibly } \\
\text { Related to } \\
\text { Volatiles } \\
\text { Metabolism }\end{array}$ \\
\hline & & & & & synthase 2 & & \\
\hline & Prupe.2G160700 & 0.999 & 2 & Up_O1 & $\begin{array}{l}\text { (+)-neomenthol } \\
\text { dehydrogenase }\end{array}$ & AT3G61220 & \\
\hline $\begin{array}{l}\text { Telomerase } \\
\text { biogenesis }\end{array}$ & Prupe.6G137000 & 0.998 & 1 & Up_O1 & RuvB-like protein 1 & AT5G22330 & \\
\hline \multirow[t]{3}{*}{$\begin{array}{l}\text { Vacuolar Protein } \\
\text { Sorting }\end{array}$} & Prupe.1G453100 & 0.5 & 1 & Up_O1 & $\begin{array}{l}\text { AP-4 COMPLEX SUBUNIT } \\
\text { BETA-1 }\end{array}$ & AT5G11490 & \\
\hline & Prupe.2G056200 & 1 & 4 & Up_O1 & $\begin{array}{l}\text { AP-4 complex subunit } \\
\text { epsilon-1 (AP4E1) }\end{array}$ & AT1G31730 & \\
\hline & Prupe.1G365900 & 0.39 & 0 & Up_O1 & $\begin{array}{l}\text { AP-2 complex subunit sigma- } \\
1 \text { (AP2S1) }\end{array}$ & AT1G47830 & \\
\hline \multirow[t]{8}{*}{$\begin{array}{l}\text { Vesicles } \\
\text { Trafficking }\end{array}$} & Prupe.1G181200 & 0.285 & 0 & Qualit_O1 & $\begin{array}{l}\text { Ras-related protein Rab-11A } \\
\text { (RAB11A) }\end{array}$ & AT1G05810 & \\
\hline & Prupe.1G486400 & 0.27 & 0 & Qualit_O1 & $\begin{array}{l}\text { TRAFFICKING PROTEIN } \\
\text { PARTICLE COMPLEX SUBUNIT } \\
9\end{array}$ & AT5G11040 & \\
\hline & Prupe.8G013500 & 0.998 & 2 & Up_O1 & $\begin{array}{l}\text { Ras-related protein Rab-18 } \\
\text { (RAB18) // protein } \\
\text { phosphatase } 1 \mathrm{~L} \text { [EC:3.1.3.16] } \\
\text { (PPM1L, PP2CE) }\end{array}$ & AT1G43890 & \\
\hline & Prupe.3G293600 & 0.53 & 1 & Up_O1 & Golgin candidate 6 & AT3G27530 & \\
\hline & Prupe.2G271800 & 0.769 & 1 & Up_O1 & $\begin{array}{l}\text { RAS-RELATED PROTEIN } \\
\text { RABD2B-RELATED }\end{array}$ & AT5G47200 & \\
\hline & Prupe.1G555300 & 1 & 6 & Up_O1 & PATELLIN-3-RELATED & AT1G72160 & \\
\hline & Prupe.8G192300 & 1 & 1 & Up_O1 & $\begin{array}{l}\text { Ras-related protein Rab-11A } \\
\text { (RAB11A) }\end{array}$ & AT3G07410 & \\
\hline & Prupe.6G024700 & 0.999 & 2 & Up_O1 & $\begin{array}{l}\text { Transmembrane emp24 } \\
\text { domain-containing protein } \\
\text { p24beta2 }\end{array}$ & AT3G07680 & \\
\hline $\begin{array}{l}\text { Vesicles } \\
\text { Trafficking/Redox } \\
\text { Metabolism }\end{array}$ & Prupe.6G134600 & 1 & 2 & Up_O1 & $\begin{array}{l}\text { VESICLE-ASSOCIATED } \\
\text { MEMBRANE PROTEIN } 714\end{array}$ & AT5G22360 & \\
\hline \multicolumn{8}{|l|}{ Upregulated $\mathrm{O} 2$} \\
\hline \multirow[t]{3}{*}{ Abiotic Stress } & Prupe.3G078100 & 0.998 & 2 & Up_O2 & Chaperone protein DnaJ & AT2G22360 & \\
\hline & Prupe.2G178200 & 1 & 4 & Up_O2 & $\begin{array}{l}\text { DESICCATION-RELATED } \\
\text { PROTEIN LEA14-RELATED }\end{array}$ & AT1G01470 & \\
\hline & Prupe.7G125900 & 0.769 & 1 & Up_O2 & Aquaporin TIP1-1 & AT2G36830 & \\
\hline $\begin{array}{l}\text { Anthocyanin } \\
\text { transport }\end{array}$ & Prupe.4G111700 & 0.998 & 2 & Up_O2 & $\begin{array}{l}\text { GLUTATHIONE S- } \\
\text { TRANSFERASE OMEGA-LIKE 1- } \\
\text { RELATED }\end{array}$ & AT4G19880 & \\
\hline $\begin{array}{l}\text { Carbohydrates } \\
\text { Metabolism }\end{array}$ & Prupe.6G210900 & 0.414 & 0 & Up_O2 & $\begin{array}{l}\text { phosphoenolpyruvate } \\
\text { carboxykinase (ATP) (E4.1.1.49, } \\
\text { pckA) }\end{array}$ & AT4G37870 & \\
\hline $\begin{array}{l}\text { Carbohydrates/ } \\
\text { Energy } \\
\text { Metabolism }\end{array}$ & Prupe.1G105800 & 0.118 & 0 & Qualit_O2 & $\begin{array}{l}\text { [Pyruvate dehydrogenase } \\
\text { (acetyl-transferring)] kinase / } \\
\text { Pyruvate dehydrogenase } \\
\text { kinase (phosphorylating) }\end{array}$ & AT3G06483 & YES \\
\hline $\begin{array}{l}\text { Cargo Delivery } \\
\text { into the } \\
\text { Peroxisome }\end{array}$ & Prupe.6G036900 & 1 & 3 & Qualit_O2 & peroxin-5 (PEX5, PXR1) & AT5G56290 & \\
\hline $\begin{array}{l}\text { Carotenoid } \\
\text { Biosynthetic }\end{array}$ & Prupe.6G340000 & 1 & 10 & Up_O2 & $\begin{array}{l}\text { Zeta-carotene desaturase, } \\
\text { chloroplastic/chromoplastic }\end{array}$ & AT3G04870 & \\
\hline
\end{tabular}


Table 1 Proteins differentially accumulated and with functional assignment (Continued)

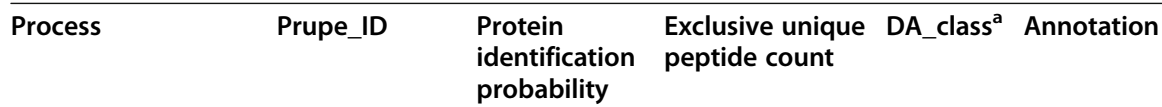

$\begin{array}{ll}\text { Best } A . & \text { Possibly } \\ \text { thaliana } & \text { Related to } \\ \text { Match } & \text { Volatiles } \\ & \text { Metabolism }\end{array}$

\begin{tabular}{|c|c|c|c|c|c|c|c|}
\hline Process & & & & & & & \\
\hline \multirow{8}{*}{$\begin{array}{l}\text { Cell Wall } \\
\text { Metabolism }\end{array}$} & Prupe.4G262200 & 0.598 & 1 & Qualit_O2 & Polygalacturonase (PpPG22) & AT3G59850 & \\
\hline & Prupe.4G261900 & 0.747 & 1 & Up_O2 & Polygalacturonase (PpPG21) & AT3G59850 & \\
\hline & Prupe.2G300900 & 0.99 & 1 & Qualit_O2 & Probable polygalacturonase & AT3G48950 & \\
\hline & Prupe.3G050200 & 1 & 3 & Up_O2 & BETA-GALACTOSIDASE 1 & AT3G13750 & \\
\hline & Prupe.5G131300 & 0.977 & 1 & Up_O2 & $\begin{array}{l}\text { ENDO-1,4-BETA-GLUCANASE } \\
\text { PpEG1 }\end{array}$ & AT1G02800 & \\
\hline & Prupe.6G075100 & 0.995 & 1 & Up_O2 & Expansin 3 (РpExp3) & AT2G39700 & \\
\hline & Prupe.4G157600 & 0.474 & 0 & Up_O2 & $\begin{array}{l}\text { PROTEIN TRICHOME } \\
\text { BIREFRINGENCE-LIKE } 41\end{array}$ & AT3G14850 & \\
\hline & Prupe.1G114500 & 0.745 & 1 & Up_O2 & $\begin{array}{l}\text { Plant invertase/pectin } \\
\text { methylesterase inhibitor } \\
\text { (PMEI) }\end{array}$ & AT1G47960 & \\
\hline $\begin{array}{l}\text { Chloroplast } \\
\text { Division }\end{array}$ & Prupe.4G013700 & 0.5 & 1 & Up_O2 & $\begin{array}{l}\text { Tetratricopeptide repeat } \\
\text { protein } 1\end{array}$ & AT1G62390 & \\
\hline Endocytosis & Prupe.6G275500 & 0.998 & 2 & Up_O2 & CLATHRIN LIGHT CHAIN 2 & AT3G51890 & \\
\hline \multirow[t]{3}{*}{$\begin{array}{l}\text { Energy } \\
\text { Metabolism }\end{array}$} & Prupe.6G244100 & 1 & 3 & Up_O2 & $\begin{array}{l}\text { ADENYLATE KINASE 1, } \\
\text { MITOCHONDRIAL-RELATED }\end{array}$ & AT2G37250 & \\
\hline & Prupe.3G092100 & 0.998 & 2 & Up_O2 & $\begin{array}{l}\text { NADH dehydrogenase } \\
\text { [ubiquinone] flavoprotein 2, } \\
\text { mitochondrial }\end{array}$ & AT4G02580 & \\
\hline & Prupe.6G249900 & 1 & 7 & Up_O2 & $\begin{array}{l}\text { INORGANIC } \\
\text { PYROPHOSPHATASE-LIKE } \\
\text { PROTEIN }\end{array}$ & AT3G53620 & \\
\hline \multirow[t]{3}{*}{$\begin{array}{l}\text { Hormones } \\
\text { Metabolism }\end{array}$} & Prupe.3G209900 & 0.643 & 1 & Up_O2 & $\begin{array}{l}\text { 1-aminocyclopropane-1- } \\
\text { carboxylate oxidase (ACO1) }\end{array}$ & AT1G05010 & \\
\hline & Prupe.1G111900 & 0.996 & 1 & Up_O2 & $\begin{array}{l}\text { GIBBERELLIN 2-BETA- } \\
\text { DIOXYGENASE } 4\end{array}$ & AT1G02400 & YES \\
\hline & Prupe.7G188800 & 1 & 2 & Up_O2 & $\begin{array}{l}\text { 2-OXOGLUTARATE (2OG) AND } \\
\text { FE(II)-DEPENDENT } \\
\text { OXYGENASE-LIKE PROTEIN }\end{array}$ & AT1G14130 & \\
\hline $\begin{array}{l}\text { Lactones } \\
\text { biosynthesis }\end{array}$ & Prupe.6G192200 & 0.244 & 0 & Qualit_O2 & $\begin{array}{l}\text { SERINE/THREONINE-PROTEIN } \\
\text { KINASE SRK2C }\end{array}$ & AT1G78290 & YES \\
\hline Lipids Metabolism & Prupe.7G076500 & 0.998 & 2 & Qualit_O2 & $\begin{array}{l}\text { Omega- } 6 \text { fatty acid } \\
\text { desaturase, endoplasmic } \\
\text { reticulum isozyme } 2\end{array}$ & AT3G12120 & YES \\
\hline $\begin{array}{l}\text { Lipids/Hormones } \\
\text { Metabolism }\end{array}$ & Prupe.1G332000 & 0.769 & 1 & Qualit_O2 & Probable peroxygenase 4 & AT1G70670 & YES \\
\hline $\begin{array}{l}\text { Lipids } \\
\text { Metabolism/ } \\
\text { Signaling }\end{array}$ & Prupe.4G089300 & 1 & 2 & Up_O2 & $\begin{array}{l}\text { GLYCOLIPID TRANSFER } \\
\text { PROTEIN-RELATED }\end{array}$ & AT2G34690 & \\
\hline $\begin{array}{l}\text { MicroRNAs } \\
\text { processing }\end{array}$ & Prupe.6G153800 & 0.5 & 1 & Up_O2 & $\begin{array}{l}\text { ARSENITE-RESISTANCE } \\
\text { PROTEIN } 2\end{array}$ & AT2G27100 & \\
\hline $\begin{array}{l}\text { Mitotic Cell Cycle } \\
\text { Progression }\end{array}$ & Prupe.1G154700 & 0.503 & 1 & Up_O2 & $\begin{array}{l}\text { RAN GTPase-activating protein } \\
2\end{array}$ & AT5G19320 & \\
\hline $\begin{array}{l}\text { Nuclear } \\
\text { Morphology and } \\
\text { Heterochromatin } \\
\text { Organization }\end{array}$ & Prupe.6G214100 & 0.621 & 1 & Qualit_O2 & $\begin{array}{l}\text { Putative nuclear matrix } \\
\text { constituent protein 1-like } \\
\text { protein }\end{array}$ & AT5G65770 & \\
\hline $\begin{array}{l}\text { Protein } \\
\text { Degradation/ } \\
\text { Signaling }\end{array}$ & Prupe.1G040200 & 0.383 & 0 & Qualit_O2 & $\begin{array}{l}\text { E3 UBIQUITIN-PROTEIN LIGASE } \\
\text { XBAT35-RELATED }\end{array}$ & AT3G23280 & \\
\hline
\end{tabular}


Table 1 Proteins differentially accumulated and with functional assignment (Continued)

\begin{tabular}{|c|c|c|c|c|c|c|c|}
\hline Process & Prupe_ID & $\begin{array}{l}\text { Protein } \\
\text { identification } \\
\text { probability }\end{array}$ & $\begin{array}{l}\text { Exclusive unique } \\
\text { peptide count }\end{array}$ & DA_class ${ }^{a}$ & Annotation & $\begin{array}{l}\text { Best } A \text {. } \\
\text { thaliana } \\
\text { Match }\end{array}$ & $\begin{array}{l}\text { Possibly } \\
\text { Related to } \\
\text { Volatiles } \\
\text { Metabolism }\end{array}$ \\
\hline & Prupe.7G170300 & 1 & 4 & Up_O2 & $\begin{array}{l}\text { 26S proteasome regulatory } \\
\text { subunit N10 (PSMD4, RPN10) }\end{array}$ & AT4G38630 & \\
\hline \multirow[t]{2}{*}{ Protein Folding } & Prupe.1G348800 & 0.745 & 1 & Up_O2 & $\begin{array}{l}\text { prefoldin alpha subunit (pfdA, } \\
\text { PFDN5) }\end{array}$ & AT5G23290 & \\
\hline & Prupe.1G118100 & 0.655 & 0 & Up_O2 & $\begin{array}{l}\text { Peptidyl-prolyl cis-trans } \\
\text { isomerase CYP21-3, } \\
\text { mitochondrial }\end{array}$ & AT3G66654 & \\
\hline \multirow[t]{5}{*}{ Protein Synthesis } & Prupe.7G265100 & 1 & 11 & Up_O2 & $\begin{array}{l}\text { EUKARYOTIC TRANSLATION } \\
\text { INITIATION FACTOR } 4 \text { GAMMA }\end{array}$ & AT5G57870 & \\
\hline & Prupe.1G274500 & 0.998 & 2 & Up_O2 & $\begin{array}{l}\text { Large subunit ribosomal } \\
\text { protein } \mathrm{L} 34 \mathrm{e}\end{array}$ & AT1G26880 & \\
\hline & Prupe.5G147500 & 1 & 4 & Up_O2 & $\begin{array}{l}\text { Large subunit ribosomal } \\
\text { protein L7Ae (RP-L7Ae, RPL7A) }\end{array}$ & AT3G62870 & \\
\hline & Prupe.6G192100 & 0.564 & 1 & Up_O2 & $\begin{array}{l}\text { Small subunit ribosomal } \\
\text { protein S6e (RP-S6e, RPS6) }\end{array}$ & AT5G10360 & \\
\hline & Prupe.7G268100 & 1 & 3 & Up_O2 & $\begin{array}{l}\text { Small subunit ribosomal } \\
\text { protein S24e (RP-S24e, RPS24) }\end{array}$ & AT5G28060 & \\
\hline \multirow[t]{2}{*}{ Protein Targeting } & Prupe.7G179600 & 0.227 & 0 & Up_O2 & $\begin{array}{l}\text { PROTEIN GLUTAMINE } \\
\text { DUMPER } 7\end{array}$ & AT5G66030 & \\
\hline & Prupe.1G362200 & 1 & 5 & Up_O2 & Early endosome antigen 1 & AT1G20110 & \\
\hline Protein Transport & Prupe.5G110100 & 0.998 & 2 & Up_O2 & RETICULON-LIKE PROTEIN B4 & AT4G11220 & \\
\hline \multirow[t]{2}{*}{$\begin{array}{l}\text { Regulation of } \\
\text { Transcription }\end{array}$} & Prupe.1G054700 & 0.5 & 1 & Qualit_O2 & $\begin{array}{l}\text { STRUCTURAL MAINTENANCE } \\
\text { OF CHROMOSOMES SMC } \\
\text { FAMILY MEMBER }\end{array}$ & AT3G23980 & \\
\hline & Prupe.8G189400 & 0.368 & 0 & Up_O2 & $\begin{array}{l}\text { DnaJ homolog subfamily C } \\
\text { member } 2 \text { (DNAJC2) }\end{array}$ & AT3G11450 & \\
\hline $\begin{array}{l}\text { Regulation of } \\
\text { Translation }\end{array}$ & Prupe.6G360600 & 0.567 & 0 & Qualit_O2 & $\begin{array}{l}\text { PROTEIN PHOSPHATASE } \\
\text { RELATED }\end{array}$ & AT3G02830 & \\
\hline \multirow[t]{5}{*}{ RNA Splicing } & Prupe.4G042600 & 0.101 & 0 & Qualit_O2 & $\begin{array}{l}\text { splicing factor 3B subunit } 2 \\
\text { (SF3B2, SAP145, CUS1) }\end{array}$ & AT4G21660 & \\
\hline & Prupe.7G153200 & 0.23 & 0 & Up_O2 & $\begin{array}{l}\text { U1 small nuclear } \\
\text { ribonucleoprotein } 70 \mathrm{kDa} \\
\text { (SNRP70) }\end{array}$ & AT3G50670 & \\
\hline & Prupe.8G029000 & 0.5 & 1 & Up_O2 & $\begin{array}{l}\text { ATP-dependent RNA helicase } \\
\text { DDX23/PRP28 (DDX23, PRP28) }\end{array}$ & AT2G33730 & \\
\hline & Prupe.6G190500 & 0.536 & 0 & Qualit_O2 & $\begin{array}{l}\text { SNW domain-containing } \\
\text { protein } 1 \text { (SNW1, SKIIP, SKIP) }\end{array}$ & AT1G77180 & \\
\hline & Prupe.6G349400 & 0.564 & 1 & Up_O2 & $\begin{array}{l}\text { Cell division cycle 5-like } \\
\text { protein }\end{array}$ & AT1G09770 & \\
\hline $\begin{array}{l}\text { RNA-mediated } \\
\text { Post- } \\
\text { transcriptional } \\
\text { Gene Silencing }\end{array}$ & Prupe.6G115400 & 0.395 & 0 & Up_O2 & Protein argonaute 5 & AT2G27880 & \\
\hline Senescence & Prupe.7G173400 & 0.5 & 1 & Up_O2 & $\begin{array}{l}\text { LA-RELATED PROTEIN 1B- } \\
\text { RELATED }\end{array}$ & AT4G35890 & \\
\hline \multirow[t]{3}{*}{ Signaling } & Prupe.4G021300 & 0.571 & 1 & Up_O2 & $\begin{array}{l}\text { CALCIUM-DEPENDENT } \\
\text { PROTEIN KINASE } 29\end{array}$ & AT4G04720 & \\
\hline & Prupe.8G057600 & 0.567 & 1 & Up_O2 & $\begin{array}{l}\text { SERINE/THREONINE-PROTEIN } \\
\text { KINASE }\end{array}$ & AT4G09570 & \\
\hline & Prupe.2G134200 & 0.998 & 2 & Up_O2 & $\begin{array}{l}\text { Nuclear pore glycoprotein } \\
\text { p62 }\end{array}$ & AT2G45000 & \\
\hline Sugar Transport & Prupe.8G101200 & 0.998 & 2 & Up_O2 & POLYOL TRANSPORTER 5 & AT3G18830 & \\
\hline
\end{tabular}


Table 1 Proteins differentially accumulated and with functional assignment (Continued)

\begin{tabular}{|c|c|c|c|c|c|c|c|}
\hline Process & Prupe_ID & $\begin{array}{l}\text { Protein } \\
\text { identification } \\
\text { probability }\end{array}$ & $\begin{array}{l}\text { Exclusive unique } \\
\text { peptide count }\end{array}$ & DA_class ${ }^{a}$ & Annotation & $\begin{array}{l}\text { Best } A \text {. } \\
\text { thaliana } \\
\text { Match }\end{array}$ & $\begin{array}{l}\text { Possibly } \\
\text { Related to } \\
\text { Volatiles } \\
\text { Metabolism }\end{array}$ \\
\hline & & & & & PePOL5 & & \\
\hline \multirow[t]{3}{*}{$\begin{array}{l}\text { Specialized } \\
\text { Metabolsim }\end{array}$} & Prupe.5G106300 & 0.772 & 1 & Up_O2 & $\begin{array}{l}\text { 2-C-methyl-D-erythritol 2,4- } \\
\text { cyclodiphosphate synthase / } \\
\text { MECDP-synthase }\end{array}$ & AT1G63970 & \\
\hline & Prupe.8G032700 & 0.607 & 1 & Up_O2 & $\begin{array}{l}\text { Sterol 3-beta- } \\
\text { glucosyltransferase }\end{array}$ & AT1G43620 & \\
\hline & Prupe.3G097700 & 0.5 & 1 & Up_O2 & $\begin{array}{l}\text { cinnamoyl-CoA reductase } \\
(\mathrm{CCR})\end{array}$ & AT1G15950 & \\
\hline \multirow[t]{2}{*}{ Vacuolar Sorting } & Prupe.7G171800 & 0.5 & 1 & Up_O2 & $\begin{array}{l}\text { VACUOLAR SORTING PROTEIN } \\
35\end{array}$ & AT2G17790 & \\
\hline & Prupe.8G143700 & 0.607 & 1 & Up_O2 & Vacuolar-sorting receptor 3 & AT2G14740 & \\
\hline
\end{tabular}

${ }^{a}$ Qualit Qualitative change in expression at a given condition, Up Upregulated (quantitative change) at a given condition

${ }^{b}$ According to Sánchez et al. An integrative "omics" approach identifies new candidate genes to impact aromavolatiles in peach fruit. BMC Genomics. 2013 May 23;14:343; Li et al. Identification of volatile and softening-related genes using digital gene expression profiles in melting peach. Tree genetics \& genomes 11.4 (2015): 71

chromosome 3; whereas the set differentially accumulated in ripe fruit was enriched in chromosome 6 (Fig. 3C). No enrichment was found after assessing all 1663 proteins identified in this study.

Among the most relevant pathways associated to proteins with differential accumulation in mature fruit, there were several that could have a direct impact in the fruit organoleptic quality: Sucrose and sorbitol conversion into fructose 6-phosphate (PWY-3801), raffinose and stachyose (PWY-5337), phenylacetaldehyde (PWY-5751), farnesyl diphosphate (PWY-5123) and glutamine (PWY-6549) biosynthesis (Fig. 4a, panels I to V). In ripe fruit, we selected the ethylene (ETHYL-PWY) and linoleoyl-CoA (PWY6001) biosynthesis pathways (Fig. 4b, panels I and II). Proteins related to cell wall disassembly were also differentially accumulated in ripe fruit (Fig. 4b, panel III). Transport reactions, such as sorbitol transport, would also be upregulated in ripe fruit (Prupe.8G101200, Table 1).

Almost all steps of the gluconeogenesis pathway (GLUCONEO-PWY) were represented by proteins characterized in this study (Fig. 4c), indicating that the pathway was active in both stages. There were very few differences in the accumulation of the proteins between mature and ripe fruit. However, subtle differences were found including the step that interconverts dihydroxyacetone phosphate (DHAP) into D-glyceraldehyde 3phosphate (EC 5.3.1.1) and the step that converts oxaloacetate into phosphoenolpyruvate (EC 4.1.1.49), with higher accumulation levels in mature and ripe fruit, respectively.

In terms of regulatory pathways, the signaling cascade that leads to the ethylene biosynthesis inhibition through the action of brassinosteroids over kinases such as the serine/threonine-protein kinase BRASSINOSTEROIDSIGNALING KINASE (BSK, Prupe.6G065600) and the receptor-like protein kinase FERONIA (Prupe.6G295900) was well represented in our mature fruit dataset (Fig. 4d).

\section{Potential biomarkers of peach fruit ripening include cell wall modifying proteins and proteins involved in plant hormone biosynthesis}

In order to determine which protein-coding genes could be used as biomarkers to differentiate between mature and ripe fruit stages, gene expression data across six developmental stages in fruit seeds and mesocarp, was plotted as heatmaps (Fig. 5, Supplementary Fig. 3A). An optimal biomarker would be a gene whose expression is low at any stage and tissue, but that achieves maximum expression in the ripe fruit mesocarp tissue. When considering protein-coding genes from mature fruit (Fig. 5a), only two proteins came close to displaying this pattern, a raffinose synthase (RAFS, Prupe.6G032400) and an endoglucanase (ENDOGL, Prupe.5G118000, Fig. 5c). When considering protein-coding genes from ripe fruit (Fig. 5b), this pattern was mainly displayed by seven protein-coding genes, six of which were clustered. These six clustered genes included three cell wall modifying proteins (polygalacturonase, Prupe.4G262200; pectin methylesterase inhibitor, Prupe.1G114500; and protein trichome birefringence-like 41, Prupe.4G157600), the main peach fruit 1-aminocyclopropane-1-carboxylate oxidase (Prupe.3G209900), an omega-6 fatty acid desaturase (Prupe.7G076500), and a thaumatin (Prupe.3G144100). The seventh protein was a gibberellin 2-beta-dioxygenase (Prupe.1G111900). Interestingly, several of these proteins were consistently found to be more abundant in mesocarp of O'Henry ripe fruit using 2D-gel electrophoresis (Supplementary Table 1, Supplementary Fig. 4) [27]. It is also interesting to note that, based on gene expression clusters, the "developmental stage" would be more relevant in terms of 


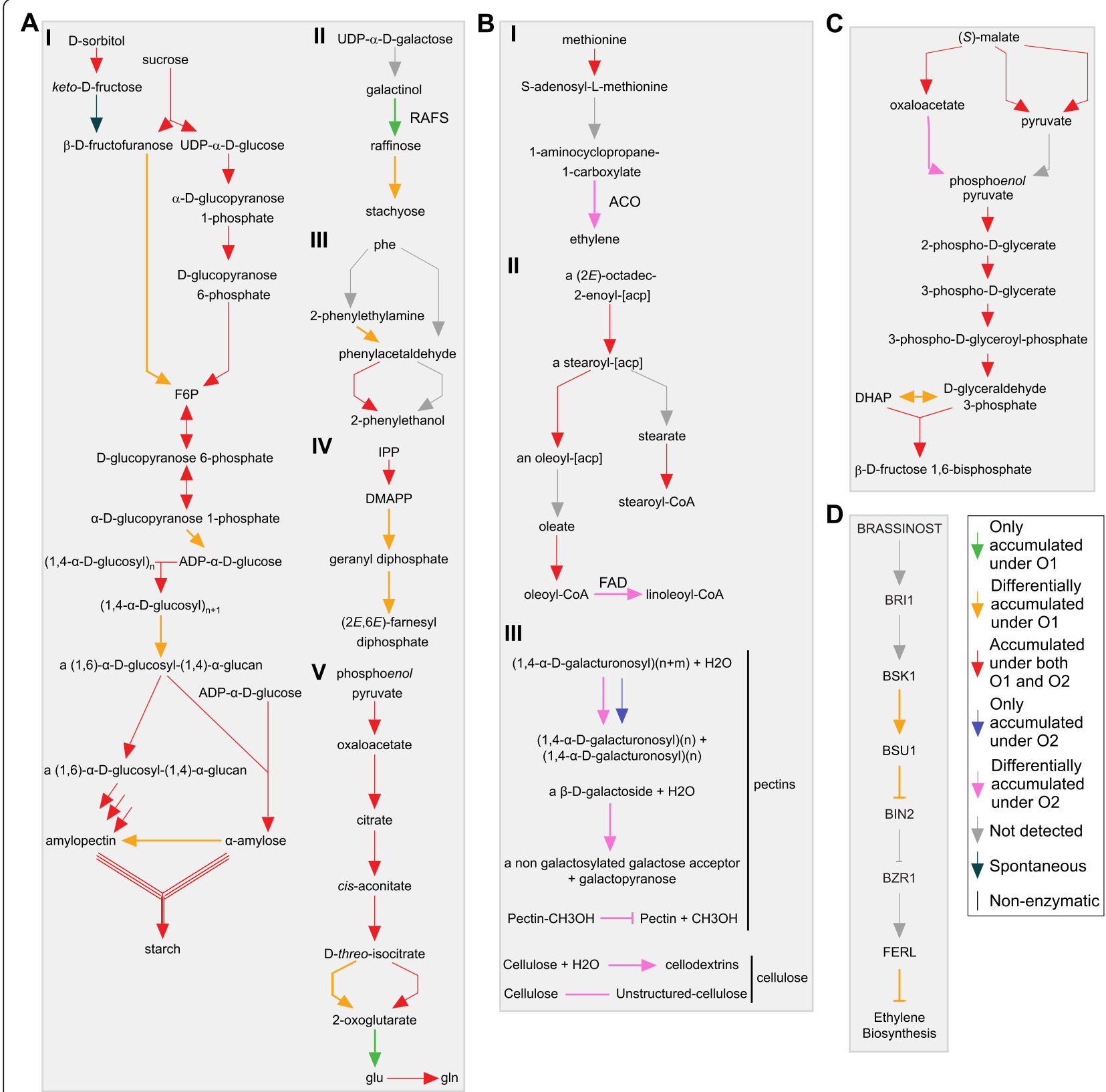

Fig. 4 Analysis of biological processes and pathways associated to differentially accumulated proteins. a Sucrose and sorbitol conversion into fructose 6-phosphate (F6P), and thereafter into starch, would preferentially occur at the mature fruit stage (panel I, MetaCyc pathways PWY-3801 and PWY-622). Raffinose and stachyose (PWY-5337), phenylacetaldehyde (PWY-5751), farnesyl diphosphate (PWY-5123) and glutamine (PWY-6549) biosynthetic pathways also had proteins that were more abundant in mature fruit (panels II to V). $\mathbf{b}$ In turn, ethylene (ETHYL-PWY) and linoleoylCoA (PWY-6001) would be preferentially synthesized in ripe fruit due to the preferential accumulation of enzymes related to these pathways at this stage (panels I and II). Cell-wall dismantling would also be favored when the fruit ripens due to the accumulation of pectin and cellulose modifying proteins and enzymes (panel III). c Gluconeogenesis (GLUCONEO-PWY) related enzymes were found accumulated in mature and ripe fruit, but with differences at the glycerone phosphate - D-glyceraldehyde 3-phosphate interconversion step (O1, EC 5.3.1.1) and the oxaloacetate conversion into phosphoenolpyruvate (O2, EC 4.1.1.49), which had differentially accumulated proteins associated to mature and ripe fruit. $\mathbf{d}$ Ethylene biosynthesis in mature fruit would be negatively modulated by the action of the signaling cascade that would begin with the action of brassinosteroids and culminate with Feronia-like receptor kinases (FERLS) action upon genes involved in ethylene biosynthesis. F-6-P - fructose 6phosphate; RAFS - raffinose synthase; phe - phenylalanine; IPP - isopentenyl diphosphate; DMAPP - prenyl diphosphate; glu - glutamate; gln glutamine; ACO - 1-aminocyclopropane-1-carboxylate oxidase; FAD - Fatty acid desaturase 


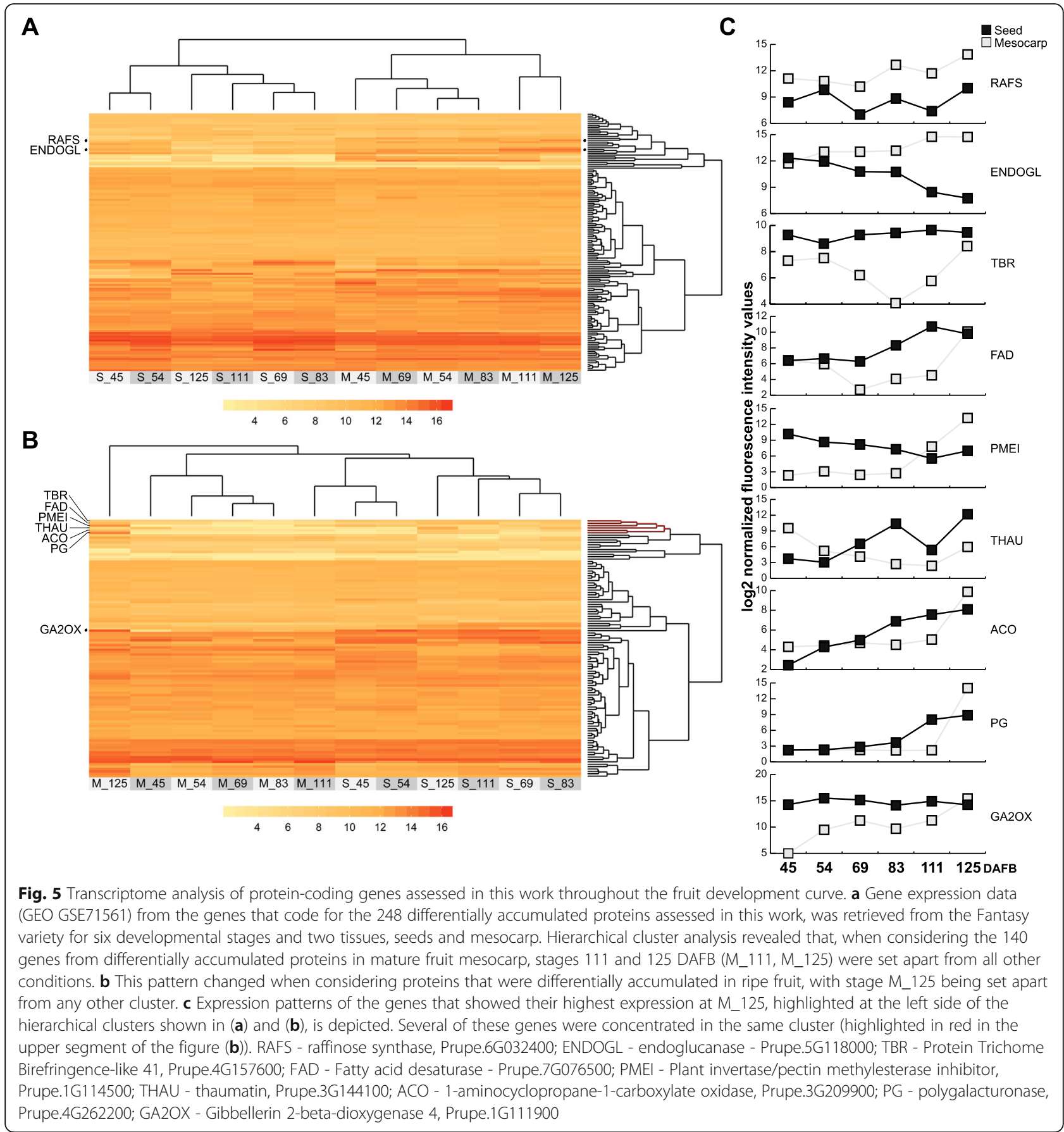

coordinating gene expression than "tissue specificity" (Supplementary Fig. 3A).

\section{Protein-coding genes involved in fruit ripening are potential targets for transcriptional factors enriched in NAC and SANT/Myb domains}

The analysis of transcription factors (TFs) that had overrepresented targets in the set of genes that coded for differentially accumulated proteins in mature and ripe fruit indicated that two different families of TFs would regulate genes expressed at mature and ripe fruit. Thus, 94, 37 and $45 \mathrm{TFs}$ were found to possess over-represented targets among the 1663 protein-coding genes assessed in this study, among those differentially accumulated in mature fruit and among those differentially accumulated in ripe fruit, respectively (Fig. 6a). The TF that targeted proteincoding genes for both mature and ripe fruit, a homeoboxleucine zipper protein ATHB-40 (Prupe.7G149700), displayed an expression profile that correlates with the ACO1 gene, i.e. a high expression peak at the stage of fruit 


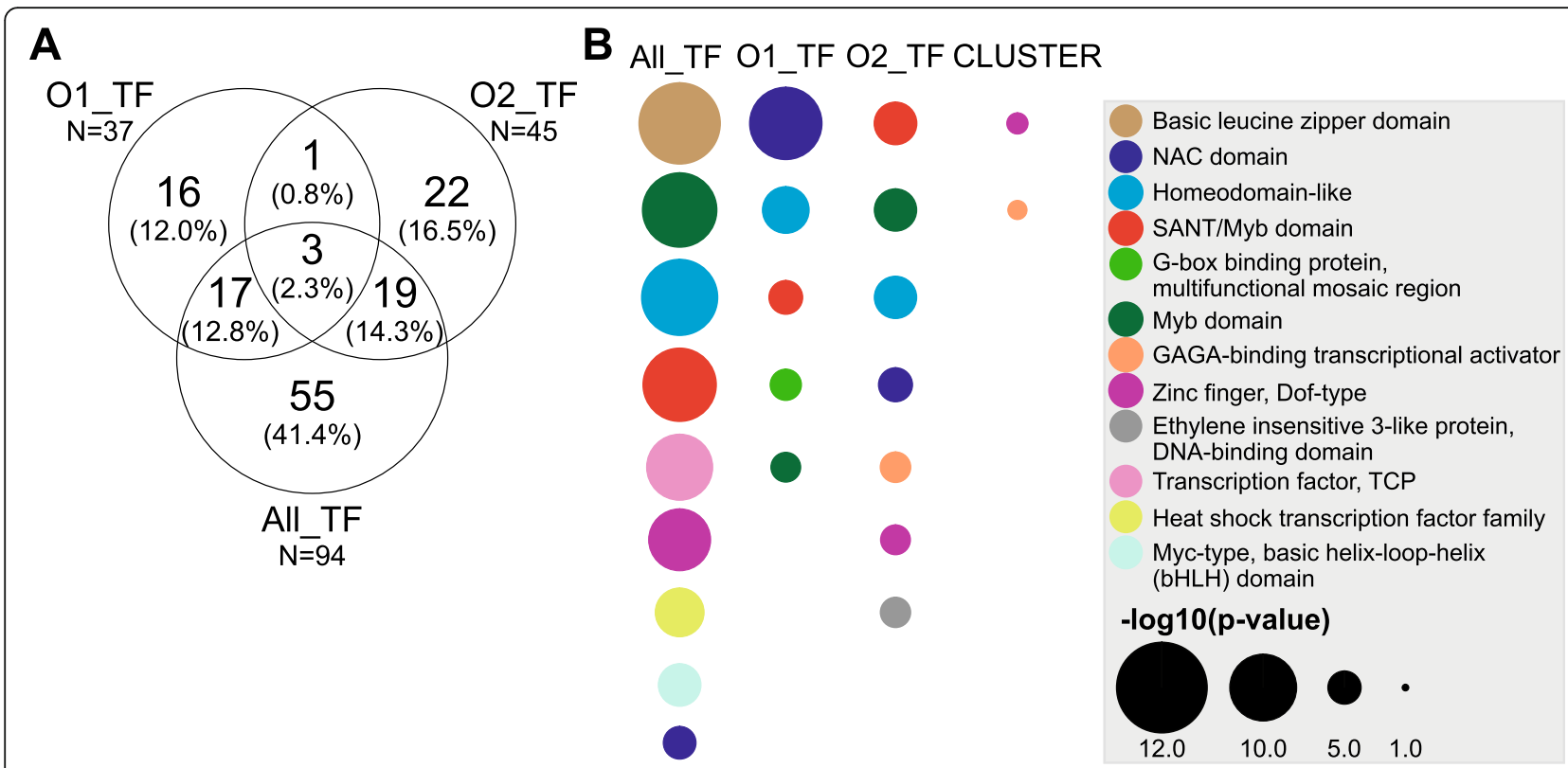

Fig. 6 Analysis of transcription factors with over-represented targets in the set of differentially accumulated proteins. a Ninety-four, thirty-seven and forty-five transcription factors (TFs) were found to have over-represented targets among the proteins assessed in this study ("ALL_TF"), those differentially accumulated in mature fruit ("O1_TF"), and those differentially accumulated in ripe fruit ("O2_TF")."). b The only TF that targeted differentially accumulated proteins in mature and ripe fruits in this study (purple labeled) was the protein Prupe.7G1499700, which displayed an accumulation pattern closely related to the one from the ACO1 (Prupe.3G209900) across the fruits developmental and ripening stages. c An analysis of TF protein domains indicated that "ALL_TF", "O1_TF" and "O2_TF" were composed of TFs with different architecture. The analysis was also extended to those TFs that targeted the seven protein-coding genes with high expression in ripe fruit ("Cluster", Fig. 4, panel (c). Time point's labels in (b) are the same as in Fig. 5

ripening (Fig. 6b). An analysis of the TF protein domains indicated that these three sets of TFs have different domain composition (Fig. 6c), with genes coding for proteins more accumulated in mature fruit displaying mainly an enrichment as targets of NAC domain TFs whereas genes from proteins more accumulated in ripe fruit being enriched as targets of MYB domain TFs.

\section{Discussion}

Proteomic approaches based on 1D electrophoresis followed by MS (Fig. 1) have been successfully used to better understand fruit ripening in Rosaceae family species such as apricot [33] and strawberry [34]. When compared to proteins extracted from ripening P. armeniaca using 1D SDS-PAGE gel followed by MS, $76 \%$ of the 245 proteins identified in mature/ripe apricot fruit were also identified in mature/ripe peach fruit [33]. Moreover when compared to other three P. persica species gel-based proteomic studies which published all the proteins characterized (Supplementary Table 3), on average an $85 \%$ of the characterized proteins matched the ones found in our study. Adding the fact that the physicochemical properties of $P$. persica primary transcripts' proteome were similar to those of the proteome analyzed in the present study (Supplementary Table 2, Supplementary Fig. 2) and that low abundant proteins, such as TFs, could be detected in our dataset, the current analysis seems to truly reflect the fruit proteome, but with a bias in terms of primarily representing proteins with average physicochemical properties (Supplementary Fig. 2). Comparison with iTRAQ proteome datasets would be highly informative, however only differentially accumulated proteins are reported in these publications with emphasis on the effect of postharvest treatments such as cold storage or disease incidence in ripening process [35-39] (Supplementary Table 3).

In order to take full advantage of the proteins characterized in systems such as ripe fruit, it is important to follow a robust pipeline of MS analysis and protein quantification, to increase the confidence in the identifications performed and to support differential accumulation analysis. MS analysis was performed using a stringent cutoff for both peptide and protein match. Next, protein quantification was performed using the average total ion chromatograms (Average TIC) [40] followed by pre-treatment data to get a data distribution as close to normal as possible (Supplementary Fig. 1), data scaling and centering, and data cleaning, to keep only those proteins that had a proper number of replicates to perform a statistical analysis of differential accumulation. All these steps explain the drop from 2740 detected proteins to 1663 assessed proteins. It is also 
worth to remember that label-free quantification, such as the one used in this work, is a good choice for proteomic analysis that seeks to characterize as many unbiased proteins as possible. However, variations are higher than in techniques that rely on labeling, since in label-free quantification samples are individually prepared and comparison occurs later, during data analysis [41]. In addition, variability among fruits in the field can be very high, even if the fruits were manually selected based on size, color and physicochemical parameters. Therefore, in many cases a protein may vary widely between different conditions, and its abundance variation due to biological and technical issues might hurdle the ability to identify this protein as differentially accumulated.

The fruit mesocarp proteome identified in this work (1663 proteins) was functionally related to carboxylic acid metabolism, intracellular transport and protein folding (Fig. 2a). Transport proteins were mainly related to carbohydrates, ions, and vesicle-mediated transport (Supplementary Table 1), with very few transporters differentially accumulated. Protein folding, in turn, was mainly related to chloroplast chaperonins [42]. Both sets point to a fruit mesocarp with active cellular compartment transport and protein folding.

Mature and ripe fruit stages are the last in the fruit developmental curve, making it possible to compare protein-coding genes from our dataset with datasets that characterized ripening-related genes in $P$. persica (GEO dataset GSE71561) [32]. Protein-coding genes expressed in mature/ripe fruit seemed to be time and tissue-specific, given that close to $25 \%$ peak their expression levels in ripe fruit when compared to other developmental stages, and 52\% peaked their expression in ripe fruit mesocarp, compared to other tissues (Fig. 2b and c). Fruit-specific genes that displayed the strongest differentiation between peach and almond (P. dulcis) were also the most highly expressed, pointing to a functional specialization of protein-coding genes that are highly expressed in fruit [43]. Our results point to the same behavior in functionally specialized fruit proteins, i.e., proteins with high accumulation in fruit could be particularly involved in its metabolism.

Samples and protein abundance differences between mature and ripe fruit mesocarp were striking, with a PCA first component splitting both samples and $14.9 \%$ of the assessed differentially accumulated proteins (Fig. 3A, Table 1). This reinforces the notion that mature and ripe fruits are different not only in terms of metabolic profiles, but also at the proteome level. Processes triggered in the mature fruit would be directed to glycogen and isocitrate metabolism, and protein localization (Fig. 3B), whereas a manual inspection indicated that protein-driven cell wall modification was much more represented in ripe fruit than in mature fruit (nine versus two proteins, Table 1, Fig. $4 \mathrm{~b}$ ). Seven of these cell wall proteins have been experimentally shown to be ethylene responsive: polygalacturonase (PG) Prupe.2G300900 [44], PpPG21 (Prupe.4G261900) [44], PpPG22 (Prupe.4G262200) [14, 44, 45], beta-galactosidase (Prupe.3G050200) [14], pectin methylesterase inhibitor (Prupe.1G114500) [46], expansin 3 (Prupe.6G075100) [45], and endo-1,4-beta-glucanase PpEG1 (Prupe.5G131300) [47], in according to the increase in ethylene production at ripe stage [28] highlighting its relevance as a ripening promoting hormone in melting peach fruit varieties. In addition, protein-coding genes from PpEG1, PpPG21, Prupe.2G300900 and Prupe.3G050200 (PpBGAL2) belonged to the same gene cluster with higher expression in ripe fruit compared to mature fruit, in the white flesh fast-melting peach "Hu Jing Mi Lu" (HJ) [48], pointing to a conserved mechanism of cell wall dismantling in peach fruits with a different genetic background. PpBGAL2 transcript was also shown to be highly correlated with the fruit softening in the melting variety $\mathrm{XH}$, with expressions 3-4 times higher during later storage compared to early storage [49].

Peach fruit size is controlled throughout its development mainly by cell divisions and enlargement of mesocarp cells [50]. These processes display a temporal control during the fruit development, with two stages of faster growth alternating with two stages of slower increases in fruit diameter, represented by a doublesigmoid growth pattern $[50,51]$. Fruit size increase during the ripening process ceases, however how this size control is accomplished is not clear. One of the mechanisms that are involved in increasing the fruit cell size is the genome size amplification by endoreduplication [52], where endopolyploid cells arise from variations of the canonical cell cycle that replicate the genome without cell division. Recently a GUANYLATE-BINDING PROTEIN1 (SlGBP1) was characterized as a possible inhibitor of cell division in tomato. This protein would maintain endopolyploid cells in a non-proliferative state [53]. The best P. persica homologue of SlGBP1 (Prupe.4G053400, 70.6\% identity) was found differentially accumulated in ripe fruit in this study, indicating that endopolyploid cells division would be inhibited during the fruit ripening, providing a molecular mechanism to explain the lack of fruit size increment in this developmental stage in peach.

\section{Key processes involved in the organoleptic changes that occur in the transition from mature to ripe fruit}

The ripening process involves changes in the fruit mesocarp flavor, color, aroma, and texture that have a direct impact on the fruit organoleptic quality. By studying the proteomic changes that are triggered during ripening, it 
would be possible to underscore some of the critical molecular processes involved in this transition. During this research, proteins involved in hormone, soluble sugars, organic acids, lipids, specialized metabolism and vesicle mediated trafficking and protein transport were correlated with this transition, and their possible role in fruit ripening is discussed below.

\section{Hormone metabolism}

There is multiple evidence that the plant hormone ethylene is involved in the regulation of the ripening process in climacteric fleshy fruit. Upon binding to its receptors, ethylene's signal is propagated to several downstream components which in turn target promoters of many ethylene-inducible genes, directly involved in the dramatic changes that occur during the transition from mature to ripe fruit [54]. The ACC synthase (ACS) and ACC oxidase (ACO) enzymes are responsible for turning S-Adenosyl methionine (SAM) into ethylene. In peach, the abundance of the ACO isoform ACO1 (Prupe.3G209900) transcript and protein correlates very closely with fruit ripening $[27,55,56]$. In this work, ACO1 also displayed a similar pattern, being more abundant in ripe fruit than in mature fruit (Table 1, Fig. 3D), validating ethylene production measured on the mature and ripe fruit stages at the molecular level [28].

The possible signaling cascades that modulate ethylene biosynthesis in climacteric fruit are poorly understood. Recently, in apple (Malus $\times$ domestica) and tomato (Solanum lycopersicum), both climacteric fruits, Feronia-like receptor kinases (FERLs) were shown to act as negative regulators of fruit ripening by inhibiting ethylene production [57]. In the current study, a $P$. persica FERL (Prupe.6G295900), with over $75 \%$ of identity with the apple MdFERL1 and the tomato SIFERL1, was characterized as more abundant in mature than in ripe fruit (Table 1). In addition, upstream key regulators of FERL, such as BRASSINOSTEROID-SIGNALING KINASE (BSK) and BRI1 SUPPRESSOR (BSU) [58], were also more abundant in mature than in ripe fruit. This pattern suggests that this signaling pathway could regulate ethylene biosynthesis during peach fruit ripening, as its downregulation in the transition from mature to ripe fruit is correlated with the increase in ethylene biosynthesis in ripe fruit.

\section{Sugar metabolism}

The sugar alcohol sorbitol is the main metabolite used to mobilize photosynthesis-derived carbohydrates from leaves to fruits in Rosaceae [59], being highly correlated with fruit taste and aroma [60], and of great interest for fruit breeders given its nutritional and sweetener qualities [61]. At a molecular level, sorbitol modulation could impact fruit quality by affecting sugar-acid balance and starch accumulation [62]. How this effect is generated is not clear, but it is postulated that sorbitol is catabolized in the cytosol, being the main driver of structural compounds biosynthesis and respiration in the peach fruit [19]. In mature fruit, sorbitol could be used to generate fructose, which in turn could be metabolized into fructose 6-phosphate (F6P), by the enzyme fructokinase (Prupe.1G196700), whose abundance is high at this stage (Fig. 4b). F6P can be used to synthesize sucrose, the predominant soluble sugar in mature fruit, or enter the glycolytic pathway [60]. A decrease in the accumulation of fructokinase in ripe fruits indicated an enhanced conversion of sucrose to fructose via suppression of sucrose synthesis and fructose phosphorylation. Similar results were observed in other peach cultivar [37], where a decrease in different isoforms of both hexokinase (ppa004610m/Prupe.1G444000) and fructokinase (ppa007069m/Prupe.3G160500) accumulation were observed in fruits ripening and senescence at room temperatures. In ripe fruit, the putative sorbitol transporter (SOT) (Prupe.8G101200) accumulated more than in mature fruit (Table 1). This protein is a close homologue to candidate SOTs in pear (PbSOT19/21) [63], apple (SOT6) [64] and sour cherry ( $P$. cerasus, PcSOT1) [65]. SOTs are represented by an expanded gene family in apple and peach [66], which is made up of 16 genes in P. persica. The ones that display the highest expression at the ripening stage were Prupe.8G101200 (PpePOL5) [67] and Prupe.3G071100 (Supplementary Fig. 3B). Thus, the PpePOL5 transporter could be partially responsible for an increase in sorbitol content in ripe fruit of the O'Henry variety, compared to mature fruit [68].

An intriguing question still under debate is about the role of stored malate in fruit metabolism during the ripening process, as malate synthesis and not dissimilation is detected throughout ripening [17]. Malate levels are mainly regulated by its synthesis due to cytosolic carboxylation of phosphoenolpyruvate (PEP), its degradation due to decarboxylation also in the cytosol or by the conversion of tri- and dicarboxylates in the mitochondria, glyoxysome or cytosol [69]. Malate can be used as a sugar precursor through gluconeogenesis, to help regulate nitrogen metabolism [17], as well as valves to balance metabolic fluxes given their function in indirect transport of reducing equivalents [70]. According to the proteomic profiles assessed in this study, malate would be catabolized by the gluconeogenesis process to different metabolites in mature and ripe fruit (Fig. 4). In mature fruit, the higher abundance of the protein triosephosphate isomerase would point to a preferred catalysis of malate to glyceraldehyde 3-phosphate, a triose phosphate that can be oxidized into pyruvate, providing the mature fruit with $\mathrm{ATP}$ and $\mathrm{NADH}$. In ripe 
fruit, the higher abundance of the enzyme phosphoenolpyruvate carboxykinase would help to keep the appropriate physicochemical conditions for the use of glutamate as nitrogen source for the biosynthesis of amino acids required at this stage [17]. Our results also indicated a decrease in other organic acids such as citrate. The enzyme pyruvate dehydrogenase kinase (PDK) inactivates the pyruvate dehydrogenase (PDH). PDK (Prupe.1G105800) was detected only in ripe fruits, thus we could argue that in ripe fruits PDH is inhibited, which could decrease the synthesis of acetyl-CoA an consequently the Krebs cycle organic acids. Our results are in agreement with very recent data by Zheng et al. [71] showing that in low acid peach cultivars such as O'Henry, PDK expression is increased in comparison to high acid peach cultivars, which would impact the citrate synthesis pathway and its accumulation.

Among the soluble sugars present in the peach fruit, sucrose, fructose and glucose do not change much during the transition from mature to ripe fruit; in contrast to xylose, fucose and raffinose, according to an assessment of $15 P$. persica varieties [2]. In the current analysis, two key enzymes involved in raffinose biosynthesis (raffinose and stachyose synthases, Table 1, Fig. 4a) were more accumulated during the mature stage, indicating that in the O'Henry variety this metabolite accumulation would occur at the mature stage. Raffinose is an important metabolite given its antioxidant properties and role in stress tolerance [2].

Starch biosynthesis and accumulation is believed to happen at the early stages of fruit development, followed by its consumption until almost undetectable levels at maturity [60]. However, enzymes involved on starch biosynthesis, such as 1,4-alpha-glucan-branching enzyme (SBE, Prupe.1G354000) and glucose-1-phosphate adenylyltransferase small subunit (APS1/AGP, Prupe.3G192600) were still detected in mature fruit, with a drop in their levels in ripe fruit (Fig. 3C). This same APS1/AGP was detected by iTraq proteome and was showed to decrease in fruits ripening at low temperatures [37]. SBE was also detected by others in the mesocarp of ripe peach fruits [72], indicating that starch biosynthesis could still be active at later stages of fruit development. Another interesting fact is the increased accumulation of the atypical cysteine/histidine-rich thioredoxin 4. P. persica homologous (ACHT4, Prupe.7G001600, 64\% identical) in ripe fruit. ACHT4 has been characterized in $A$. thaliana as a molecular switch of APS1, being able to quench APS1 activity [73]. By combining decreased accumulation of SBE and APS1 with an increase of ACHT4, the ripe fruit metabolism could downregulate starch content at this final developmental stage.

\section{Fruit aroma and lipid metabolism}

Among the many dozens of volatiles peach fruits can produce, the $\gamma$ - and $\delta$-decalactones, C6 aldehydes and alcohols, terpenoids and volatile esters are the ones that are mainly related to fruit aroma $[8,74,75]$. Volatile esters are the product of alcohol acyltransferase-mediated biosynthesis, and degradation through carboxylesterase (CXE) activity [75]. In tomato, low ester levels, which positively correlate with fruit liking, were associated to the enzyme SlCXE1 [76]. In peach, the carboxylesterase PpCXE1 (Prupe.8G121900) was shown to be able to degrade volatile acetate esters [75]. In the present study, two CXE proteins were found to be more abundant in mature fruit than in ripe fruit, Prupe.1G439300 and Prupe.8G121500. The genes coding for these proteins were top-7 and top-8 in expression level in ripe fruit, among 19 putative CXEs in P. persica [75]. Prupe.1G439300 is the best homologue to the tomato SlCXE1 [75] and its protein-coding gene displayed a peak of expression in ripe fruit (GEO dataset GSE71561), being a good candidate for further characterization.

Fruits can synthesize lactones that attract feeders for seed dispersal, mostly the $\gamma$-lactones decano-4-lactone and/or dodecano-4-lactone [77]. These compounds, which primarily derive from oleic acids or derivatives, are metabolized by a series of enzymes, including epoxide hydrolases, to generate lactones such as undecano-4lactone [77]. They can be found both in fruit skin as well as mesocarp [74]. According to our data, lactone metabolism would also be differentially regulated in mature and ripe fruit, due to preferential accumulation of epoxide hydrolase EPH2 (Prupe.7G162300) [78] in mature fruit. On the other hand, the SRK2C kinase (Prupe.6G192200), which has been correlated to lactones using QTL analysis [79], is exclusively found in ripe fruit (Table 1). The target of SRK2 is unknown, and given its high expression (GEO dataset GSE71561), differential accumulation during the ripening process (Table 1), and correlation with lactone biosynthesis, it becomes an interesting candidate for further characterization.

Fruit ripening has been characterized as a senescing process, with cell membrane deterioration being the hallmark. Phospholipase D (PLD) is among the most relevant proteins involved in cell membrane deterioration in ripening fruits, acting upon phospholipids to generate phosphatidic acid (PA) and a free head group [80]. PLD action is also able to trigger a myriad of cellular processes, and therefore its activity is tightly regulated [81]. PLDs have been grouped into five classes $(\alpha$, $\beta, \gamma, \delta$ and $\zeta$ ) according to several parameters such as domain structure and biochemical properties. Similar to most plant PLDs, PLD $\delta$ requires $\mathrm{Ca}^{2+}$ and is stimulated by phosphatidylinositol 4,5-bisphosphate (PIP2) [81]. However, Arabidopsis PLD $\delta$ displays a distinctive property, which is to be activated by oleic acid [81]. A peach PLD $\delta$ (Prupe.7G17540) was found to be more abundant in mature fruit than in ripe fruit (Table 1). 
Fatty acid desaturase 1 (FAD1, Prupe.7G076500), a $\omega$ 6 Oleate desaturase [8], displayed increased abundance in ripe fruit (Fig. 4b, panel II), a pattern similar to the one displayed by its transcript in the P. persica Yulu variety [74], in the GSE71561 dataset, and by its closest orthologue in Fragaria vesca [79]. FAD1 gene expression was also sensitive to the ethylene signal transduction pathway inhibitor 1-methylcyclopropene (1-MCP), a compound known to negatively affect peach fruit aroma [82]. This increase could imply that FAD1 could be involved in linoleic and linolenic acids biosynthesis in peach ripe fruit [8], or could be involved in $\gamma$ decalactone biosynthesis, as proposed for the $F$. vesca FaFAD1 [79].

\section{Solute transport}

Aquaporins are transmembrane proteins that enable water and small neutral solute translocation across cellular membranes. Among the different types of aquaporins, those located in the vacuolar membranes are called tonoplast intrinsic proteins (TIPs). TIPs are classified into five groups (TIP1-5), and are able to transport hydrogen peroxide and glycerol, in addition to water [83]. The P. persica aquaporin TIP1-1 (Prupe.7G125900) was found to be more abundant in ripe than in mature fruit mesocarp (Table 1). A close homologous (93\% identity) protein-coding gene from sweet cherry ( $P$. avium) was among the three most expressed aquaporins in the fruit, being mainly expressed in mesocarp throughout fruit development [84]. The P. persica PpTIP1-1 transcriptional pattern was very similar (GEO dataset GSE71561), with the gene being expressed at a regular level throughout mesocarp development. This indicates that both Prunus TIP1-1 aquaporins conserved their tissue localization and expression patterns. Moreover, it indicates that these aquaporins could be key to transport water across the vacuole in the Prunus fruit mesocarp [84].

\section{Vesicle mediated trafficking and protein transport}

Protein trafficking, mediated by vesicular transport, was also shown to be a very important process during the fruit ripening transition (Figs. 2 and 3). Vesicle transport can be divided in three broad consecutive steps: vesicle budding from a donor membrane, trafficking and fusion with a specific acceptor membrane. Prior to the fusion stage, a set of tethering factors allows the vesicle to be in close proximity to the target membrane, thus helping vesicle trafficking organization. Recently, the Transport Protein Particle (TRAPP) complex, a multisubunit tethering complex, was experimentally characterized in Arabidopsis [85], including all 13 mammalian TRAPP subunits as well as an additional plant-specific component, the TRAPP-Interacting Plant Protein (TRIPP).
TRIPP plays important roles in trafficking-dependent processes, including the formation of new cell walls and reproductive development [85]. Among the $14 \mathrm{~A}$. thaliana TRAPP subunits, we detected 7 homologues (Supplementary Table 1). Besides TRS20, TRIPP and TRS120, which have been shown to interact, were found to be more abundant in mature fruit (Table 1). Both TRIPP and TRS120 are part of TRAPPII, one of a variety of TRAPP modular forms. TRAPPII mutants displayed altered levels of methyl-esterified pectins at cell plates, pointing to a role of this complex in the transport of pectins [86]. Changes in pectin metabolism are one of the hallmarks of the softening and textural changes in melting flesh peach triggered by fruit ripening [87]. Thus, our results help to link cell wall metabolism with vesicle mediated transport of proteins and polysaccharides through the downregulation of TRIPP and TRS120 between mature and ripe fruit.

TRAPPII have also been pointed as a guanine exchange factors (GEFs) for RabA GTPases [88, 89]. RabA GTPases can regulate membrane fusion events and other cell organelle processes once they are recruited to their specific membrane compartment and activated by their cognate RabGEF. Among the proteins downregulated during the mature to ripe fruit transition we found a homologous of RABA5b, a RabA GTPase. Interestingly, the P. persica TRIPP, TRS120 and RABA5b displayed a dramatic and linear increase in transcript abundance from 81 to 125 DAP, pointing to a specific role in fruit development for these 3 proteins, and TRIPP-TRS120 TRAPPII as potential GEFs for RABA5b.

Another key component of the vesicle trafficking machinery are the adaptor protein complexes, which participate in the selection of the vesicles specific transported cargo. Using a combination of organelle density gradients with proteome analysis, PertlObermeyer et al. [90] indicated that the adaptor protein complex 4 (AP4) participates in delivering cell wall proteins. AP4 would also be involved in sorting transmembrane proteins to the vacuole [91], being a key component of the post Golgi trafficking. Alterations in the cell wall proteome content as well as active vacuolar sorting have been associated with fruit ripening [14, 92]. We detected two AP4 subunits down-regulated during the transition from mature to ripe fruit (Table 1). Together, our results indicates that an active vesicle mediated-traffic is operating at mature peach fruit, and that during the transition to ripe fruit this process shifts into a less active state, possibly associated with the fruit senescence.

\section{Transcription factors assessment}

Analysis of possible transcription factors (TFs) that could regulate protein-coding genes expressed mostly or 
specifically during fruit ripening is of high interest given its application in driving the expression of genes of interest in this organ. Their identification could help to uncover the transcription regulation that underlies the extensive changes triggered by fruit ripening. TFs associated to ripening in climacteric fruit have been identified in apricot [93, 94], melon [95], banana [96, 97], tomato [98, 99], papaya [100-102], among others. By 2015, around 1533 TFs were identified in P. persica [20], however just a few have been characterized and even less have been associated to the fruit ripening process. MADS-box PrupeSEP1 (Prupe.3G249400) [103], TCP PpTCP.A2 (Prupe.1G272500) [49], homeobox PpHB.G7 (Prupe.1G416800) [104], AP2/ERF PpERF2, PpERF3 and PpERF.E2 (Prupe.5G090800, Prupe.7G194400 and Prupe.3G032300) [54, 105], ARFs PpARF5 (Prupe.1G368300) [106] and EIN3-like PpEIL1 to 5 (Prupe.6G018200, Prupe.2G058400, Prupe.2G058500, Prupe.6G181600, Prupe.2G070300) [105] are among those TFs already characterized and associated with peach fruit ripening. NAC domain TFs were enriched among the TFs that targeted the genes whose respective proteins were more abundant in mature compared to ripe fruit. Several NAC TFs have been reported to be involved in regulating tomato [107], melon [95] and papaya [100] fruit ripening, indicating that NAC TFs role in fruit ripening is evolutionarily conserved [108]. In peach, both ACS and ACO genes, involved in ethylene biosynthesis, display NAC transcription factor binding motifs, and several NAC TFs and key fruit ripening genes display a ripening-specific expression pattern [32]. Protein-coding genes whose products were more abundant in ripe compared to mature fruit also displayed an enrichment as NAC TFs targets, however they were mainly enriched as MYB TFs targets. MYB ripening-related TFs have been characterized in Lycium ruthenicum [109], in tomato [110], in papaya [101] and in plum (P. salicina) [111], indicating that MYBs might also be key in modulating the peach fruits pigmentation, flavour, and texture changes triggered by the fruit ripening [112].

Just one TF would have as targets the protein-coding genes for both mature and ripe fruit when compared to all 1663 proteins identified in the present work. This protein was a HB40-homolog protein (Prupe.7G149700), which displayed a strong expression peak at the stage of fruit ripening (Fig. 6b). In tomato, the MADS box TF RIPENING INHIBITOR (RIN) has been placed as an early ripening regulator. The best tomato homologous of Prupe.7G149700, the gene Solyc02g085630 (64\% identity), was among the RIN targets identified by chromatin immunoprecipitation coupled with DNA microarray analysis (ChIP-chip) [113], indicating that these HB40homolog proteins could be effectors of RIN.

\section{Future perspectives}

Plant Proteomics analysis has benefited, in the last years, from the increasing development of mass spectrometry (MS), the publication of hundreds of plant genomes (430 to date) [114] and generation of customized bioinformatics tools and pipelines. 1D-gel electrophoresis followed by LC/MS-MS analysis (Fig. 1), has the great advantage of being straightforward to execute and analyze, as well as being among the most robust pipelines for proteomic analysis [115]. Besides gel based, gel free [116], antibody chips [13] and MS-imaging [117] are also available for analyzing plant sample proteome contents. However, the most promising approaches are related to how validated and integrate proteomics data with other omics approaches in order to get a more systemic vision of the processes under evaluation [118]. In this work we integrated proteomics data generated by us and others, as well as different sets of transcriptomic data publicly available to unveil information regarding critical molecular processes involved in the peach fruit ripening.

P. persica belongs to the Rosaceae family, whose species have developed a wide array of fruit types, including drupe, pome, drupetum, achene, and achenetum, making it one of the most informative plant family to perform comparative developmental and evolutionary studies [119]. P. persica displays a drupe-type of fruit, where a fleshy fruit encloses a lignified endocarp surrounding a seed. The presence of this lignified endocarp imposes a challenge to the proper fruit development and ripening, since the phenylpropanoids allocation must be carefully controlled for the endocarp lignification during development or to the biosynthesis of flavour/aroma compounds in the ripe fruit mesocarp [120]. This characteristic is particular to this kind of fruit, making the extrapolation of what is known in the so far best fleshy fruit model tomato ripening, limited. In addition, as mentioned previously, the tomato ripening regulatory circuit is mainly based on the action of MADS TFs, whereas in peach NAC-type TFs would have a predominant role in controlling the ripening regulatory circuit [32]. Assessing the molecular mechanisms, using integrated omics approaches, of plants with combinations of the slow ripening (SR) allele, which can render plants with unique phenotypes [121], as well as the results of different pre-harvest treatments $[67,122]$ that affects the fruit quality will help to uncover new key players that are probably particular to drupe-type fruits.

\section{Conclusions}

We have identified 1663 proteins with high confidence using 1D SDS-PAGE fractionation associated to MS-MS detection. Above a quarter of the genes that code for these proteins were preferentially expressed at mature- 
ripe fruit in terms of developmental stage and tissue, indicating that these proteins were mainly involved in the fruit ripening. The differentially accumulated proteins in mature and ripe fruit identified in this study showed a high correlation with previous transcriptome studies. Differentially accumulated proteins were mainly related to the metabolism of hormones such as ethylene and brassinosteroids, sugar metabolism, cell wall rearrangement, fruit aroma and lipid metabolism.

Mature fruit displayed more changes than ripe fruit, with several changes associated to well characterized pathways, in contrast to ripe fruit, where many changes could not be mapped to coordinated biochemical processes. This indicates that the metabolism of mature fruit is more regulated than the one from ripe fruit, which agrees with the idea that ripening fruit undergoes a coordinated senescence process.

The identification of proteins with a marked differential accumulation during the mesocarp fruit ripening process will help to set experimental designs that could allow a more detailed analysis of the ripening process itself. In the near future, the use of precise and reliable near infrared spectroscopy based non-destructive tools [123] together with the molecular profiling of these proteins could make possible to perform a detailed analysis of the ripening stages SI to SIII, since by now no phenotypical, anatomical, biochemical or morphological parameter can help to discriminate these stages among fruits that display, on the tree, a great variation in terms of maturity stage, hampering this assessment.

\section{Methods}

Plant material

Regular size fruit were harvested from 8-year-old 'O'Henry' trees grown on Nemaguard rootstocks in a commercial orchard located in the Aconcagua Valley, Chile ( $\left.34^{\circ} 17^{\prime} \mathrm{W}, 70^{\circ} 54^{\prime} \mathrm{S}\right)$ [28]. As harvesting index we used the change in fruit ground color, measured using fruit company's color table. Two postharvest stages were selected for proteome analysis: mature fruit $(\mathrm{O} 1)$, that consisted on firm fruit taken immediately after harvest (firmness of around $60 \mathrm{~N}$ ) and in the stage required for packing; and ripe fruit $(\mathrm{O} 2)$, that consisted on fruit ripen at $20^{\circ} \mathrm{C}$ (firmness of around $11 \mathrm{~N}$ ) [28]. Physiological parameters such as firmness, color, total soluble solids, titratable acidity, respiration rate and ethylene production were measured by Campos-Vargas et al. [28]. Three fruits from each postharvest stage were used for protein extraction and considered biological replicates (Fig. 1a).

\section{Protein extraction and SDS-PAGE}

One milligram of mesocarp tissue from each biological sample was pulverized in liquid nitrogen and transferred to a room temperature tube with $5 \mathrm{~mL}$ of protein extraction buffer [124]. This solution was mixed with $5.5 \mathrm{~mL}$ of Tris-saturated phenol $\mathrm{pH} 8.0$ and shaken vigorously for $5 \mathrm{~min}$ at room temperature, followed by centrifugation at $8500 \times \mathrm{g}$ for $14 \mathrm{~min}$ at $4{ }^{\circ} \mathrm{C}$ to achieve phase separation. The phenolic phase was recovered, reextracted with an equal volume of protein extraction buffer and precipitated for $2 \mathrm{~h}$ at $-20^{\circ} \mathrm{C}$ by the addition of five volumes of $0.1 \mathrm{M}$ ammonium acetate in methanol at $-20^{\circ} \mathrm{C}$ [26]. The precipitated material was collected by centrifugation at $8500 \times \mathrm{g}$ for $12 \mathrm{~min}$ and protein pellets were washed three times with cold ammonium acetate in methanol and once with $80 \%$ acetone at $-20^{\circ} \mathrm{C}$. The pellet was dried at room temperature and then solubilized in $300 \mu \mathrm{L}$ of resuspension buffer which contained $5 \mathrm{M}$ urea, $2 \mathrm{M}$ thiourea, $2 \%$ CHAPS $(\mathrm{w} / \mathrm{v}), 2 \% \mathrm{SB} 3-10$ (w/v), 0.5\% ampholites pH 5-7 (v/v) and 0.25\% ampholites $\mathrm{pH} 3-10(\mathrm{v} / \mathrm{v})$ [125]. Protein yield was determined by Bradford protein assay [126]. All samples were stored at $-80^{\circ} \mathrm{C}$ prior to electrophoresis.

SDS-PAGE was performed on $12 \%$ polyacrylamide gels casted on a BIO-RAD Mini-PROTEAN Tetra cell with $1 \mathrm{~mm}$ spacer plates. A hundred and fifty micrograms of protein samples were mixed with $10 \mu \mathrm{L}$ Coomassie blue $5 \mathrm{X}$ loading buffer and run at $80 \mathrm{~V}$ until the dye front reached the bottom of the gel. Band visualization was achieved by staining the gels with colloidal Coomassie G250. Only one sample was run per gel. Each lane loaded with proteins was excised and divided into ten slices of $4 \mathrm{~mm} \times 4 \mathrm{~mm} \times 1 \mathrm{~mm}$ (Fig. 1b).

\section{Experimental LC/MS/MS}

Gel slices were digested in-gel according to Shevchenko et al. [127] with modifications. Gel bands were dehydrated using $100 \%$ acetonitrile and incubated with 10 $\mathrm{mM}$ dithiothreitol in $100 \mathrm{mM}$ ammonium bicarbonate $(\mathrm{pH} 8)$ at $56^{\circ} \mathrm{C}$ for $45 \mathrm{~min}$, dehydrated again and incubated in the dark with $50 \mathrm{mM}$ iodoacetamide in $100 \mathrm{mM}$ ammonium bicarbonate for $20 \mathrm{~min}$. Gel bands were then washed with ammonium bicarbonate and dehydrated again. Sequencing grade modified trypsin was prepared to a final concentration of $0.01 \mu \mathrm{g} \mu \mathrm{L}^{-1}$ in $50 \mathrm{mM}$ ammonium bicarbonate and $50 \mu \mathrm{L}$ of this solution was added to each gel band. Bands were then incubated at $37^{\circ} \mathrm{C}$ overnight. Peptides were extracted from the gel by water bath sonication in a solution of $60 \% \mathrm{ACN} / 1 \% \mathrm{TCA}$ and vacuum dried to approximately $2 \mu \mathrm{L}$. Peptides were then re-suspended in $2 \%$ acetonitrile/ $0.1 \%$ trifluoroacetic acid to $20 \mu \mathrm{L}$. From this, $10 \mathrm{~mL}$ were automatically injected by a Waters nanoAcquity Sample Manager and loaded for 5 min onto a Waters Symmetry C18 peptide trap $(5 \mu \mathrm{m}, 180 \mu \mathrm{m} \times 20 \mathrm{~mm})$ at $4 \mu \mathrm{L} / \mathrm{min}$ in $5 \% \mathrm{ACN} /$ $0.1 \%$ formic acid. The bound peptides were then loaded onto a Waters BEH C18 nanoAcquity column $(1.7 \mu \mathrm{m}$, $100 \mu \mathrm{m} \times 100 \mathrm{~mm}$ ) and eluted for $35 \mathrm{~min}$ with a gradient 
of $5 \% \mathrm{~B}$ to $30 \% \mathrm{~B}$ in $24 \mathrm{~min}$, ramped up to $90 \% \mathrm{~B}$ at 25 min and held for $1 \mathrm{~min}$, then dropped back to $5 \% \mathrm{~B}$ at 26.1 min using a Waters nanoAcquity UPLC (Buffer $\mathrm{A}=$ 99.9\% water $/ 0.1 \%$ formic acid; Buffer $B=99.9 \%$ acetonitrile $/ 0.1 \%$ formic acid) with a constant flow rate of $0.8 \mu \mathrm{L} \mathrm{min}^{-1}$.

Eluted peptides were sprayed into a ThermoFisher LTQ Linear Ion trap mass spectrometer outfitted with a MICHROM Bioresources ADVANCE nano-spray source. The top five ions in each survey scan were then subjected to data-dependent zoom scans followed by low energy collision induced dissociation (CID) and the resulting MS/MS spectra were converted to peak lists in BioWorks Browser v3.2 (www.thermo.com) using the default LTQ instrument parameters. Peak lists were searched against a custom database containing protein sequences from Prunus persica whole genome assembly, v1.0 and common laboratory contaminants (downloaded from NCBI, www.ncbi.nlm.nih.gov) using the Mascot searching algorithm, v2.3 (www.matrixscience.com). Mascot parameters for all databases were as follows: allow up to two missed tryptic sites; fixed modification of carbamidomethyl cysteine; variable modification of oxidation of methionine; peptide tolerance of $+/-200$ $\mathrm{ppm}$; MS/MS tolerance of $0.6 \mathrm{Da}$; peptide charge state limited to $+2 /+3$ (Fig. 1c). Translation from v1.0 genome annotation to version 2.1 was achieved by using data provided by Phytozome v12 [128] and by manual analysis of the peptides characterized.

\section{Data processing}

The Mascot output was analyzed using Scaffold v4.8.2 (www.proteomesoftware.com) to statistically support protein identifications. Assignments were validated in Scaffold according to the following criteria: Protein Threshold - 1.0\% FDR; Minimum number of peptides 1 ; Peptide threshold - $0.1 \%$ FDR. To be able to accurately determine changes in protein levels, average total ion chromatograms (Average TIC) was retrieved from Scaffold for each protein assessed in each of the six samples under evaluation [40]. Average TIC for each protein was estimated using only those peptides identified with high confidence (Fig. 1d). Supporting material and protein datasets has been deposited to MassIVE platform under accession number MSV000086519 or ftp:// massive.ucsd.edu/MSV000086519/.

\section{Data pre-treatment}

To circumvent the issue of missing data, average values were calculated for those proteins that had only two biological replicates per biological condition (mature or ripe) and were used as third replicate. All the following analyses were thus performed with proteins which had at least two data points in $\mathrm{O} 1$ and $\mathrm{O} 2$, being the other proteins discarded. Protein data was scaled by using pareto scaling [129], normalized using Quantile Normalized procedure and centered at zero by subtracting the mean value, using InfernoRDN (version 1.1.5970.31895) [130]. This allowed the data to be transformed to achieve a close to normal distribution, required for many statistical analyses of variance (Supplementary Fig. 1). Q-Q and Box-plot graphs were also performed using InfernoRDN.

\section{Assessment of the physicochemical characteristics of proteins}

Proteins derived from the primary transcript of each of the 26,973 protein-coding genes (Ppersica_298_v2.1.protein_primaryTranscriptOnly.fa) were retrieved from Phytozome v12 [128] and were assessed using the Peptides R Package [131]. The following parameters were evaluated for each protein: length, molecular weight (MW, in Daltons), charge $(\mathrm{pH}=7$, pKscale $=$ "Lehninger"), protein stability (instability index), and hydrophobicity (KyteDoolittle and Guy scale). Mean values and Gini's mean difference, a measure of variability that is robust even for non-normal data distributions, were computed using the Hmisc R Package.

\section{Evaluation of protein differential accumulation}

To detect differences in protein accumulation in mature and ripe fruits, a two-sample t-statistics with equal variance was performed for each protein/gene under analysis using the Bioconductor 'multtest' package followed by the "ABH" (Adaptive Benjamini-Hochberg) correction procedure, with a cutoff value of 0.1 .

\section{Gene ontology and pathways analysis}

Gene ontology analysis was performed using Phytomine (https://phytozome.jgi.doe.gov/phytomine/begin.do). The Benjamini-Hochberg test, with a "max $p$-value" set to 0.05, was used for Multiple Testing Corrections. Redundant GO terms were removed with the webtool REVI GO [132], using the following parameters: 1. Allowed similarity: small (0.5); 2 . GO categories associated to: $p$ values; 3. GO term sizes database: Arabidopsis thaliana; 4. Semantic similarity measure to use: SimRel. Next, CirGO [133] was used to plot a concise version of the $\mathrm{GO}$ analysis.

Pathway diagrams were built by first running the program DeepEC [134] to annotate the enzymes included in the 26,873 protein-coding genes from the $P$. persica genome version 2.1. Next, this annotation was used to generate the input file for the program Pathway Tools [135], which was used to infer the pathways and reactions from P. persica (Supplementary table 1). 
Principal component analysis (PCA)

PCA analysis was run on normalized and centered data using the Explore/PCA tool from InfernoRDN [129].

\section{Transcriptional analysis of the gene expression omnibus dataset GSE71561}

Data from 13 peach samples, which included six samples from fruit seeds (days 41, 54, 69, 83, 111 and 125 after full bloom - DAFB), the same six samples from fruit mesocarp and one sample from flowers from the midseason Fantasia variety, was downloaded from the GSE71561 dataset. Thus, samples covered until the commercial ripening stage.

The microarray data was $\log 2$ transformed following the protocol available from the online tool GEO2R [136]. This data, representing 29,045 genes, was used to generate heatmaps using the "superheat" $\mathrm{R}$ package [137]. The main set parameters were: clustering.method = "hierarchical", dist. method = "maximum", linkage.method = "complete". In order to avoid dealing with probes that target the same gene, all genes were ranked according to their average abundance, and then those genes with repeated measures and lower average abundances were removed. Subsets of this data, such as expression patterns from selected protein-coding genes were also plotted as heatmaps using the same parameters.

In addition, data from mesocarp tissue was used to contrast the expression of genes in the 125 DAFB stage against the remaining five mesocarp samples (M_125 vs M_41, M_125 vs M_54, M_125 vs M_69, M_125 vs M_ 83, M_125 vs M_111). This task was performed using the Limma R package [138], following the protocol available from the online tool GEO2R [136] and using the "decideTests" function. To improve the statistical confidence of the analysis, the probes that targeted the same gene had to display the same "decideTests" results in order to be considered for further analysis. This approach reduced the original dataset size from 29,045 genes to 18,074 genes $(62.2 \%)$. These 18,074 genes included information from 1136 protein-coding genes $(68.3 \%)$ present in our proteomics dataset.

\section{Retrieval and analysis of transcription factors regulatory elements}

Transcription factors (TFs) that possessed overrepresented targets in the protein set differentially accumulated in mature and ripe fruits and among all the proteins assessed in this study, were retrieved from the Plant Transcription Factor Database (PlantTFDB) [139], using the "Regulation Prediction" tool from the Plant Transcriptional Regulatory Map. Next, Phytomine (https://phytozome.jgi.doe.gov/phytomine/begin.do) was used to retrieve protein domains enriched for these TFs.
The Benjamini-Hochberg test, with a "max $p$-value" set to 0.05 , was used for Multiple Testing Corrections.

\section{Gene family number analysis}

$P$. persica gene family numbers were retrieved from PLAZA 4.0 [140], using the respective $P$. persica genome v2.1 ID as identifier.

\section{Supplementary Information}

The online version contains supplementary material available at https://doi. org/10.1186/s12864-020-07299-y.

Additional file 1: Supplementary Fig. 1. Data pre-treatment. In order to have an insight about the data distribution, Q-Q plots were generated using as input the raw (A), versus imputed-scaled-centered protein abundance data (C). As a result from pre-treatment data, the Q-Q plot curve fitted much closer to the normal expectation curve (straight red diagonal line) than with the raw data. Boxplots of raw (B) vs treated data (D) further highlighted how the data became centered and scaled after been pre-treated.

Additional file 2: Supplementary Fig. 2. Proteome bias assessment. Protein parameters were compared among P. persica primary transcripts' proteome (left panels), current proteome (middle panels) and a mesocarp-derived proteome extracted from juicy and mealy fruits from the Spring Lady variety (right panels) [30]. Panels I to III contrast proteomes in terms of length and molecular weights (MW). Panels IV to VI contrast proteomes in terms of charge and protein stability based on its amino acids (instalindex). Panels VII to IX contrast proteomes in terms of hydrophobicity, using two scales: KyteDoolittle and Guy. Each dot in each graph represents the intersection of the values one protein has for the two parameters under evaluation. The distributions of values for each of these two parameters are shown above and at the right side of each panel as density plots.

Additional file 3: Supplementary Fig. 3. Hierarchical clustering of all genes transcriptionally characterized in the GSE71561 dataset and a subset related to sorbitol biosynthesis. Transcriptional information (average of three replicates of $\log 2$ normalized fluorescence intensity values) from 29,045 genes from the peach fruit genome 1.0, assessed in 13 conditions, was displayed using hierarchical clustering and the following conditions: clustering. method = "hierarchical",

dist. method = "maximum", linkage. method = "complete"(panel I). Using the same stages, data from genes encoding a putative sorbitol transporter family is also depicted (panel II). S_45 to S_125, seed samples at $45,54,69,83,111$ and 125 days after full bloom (DAFB); M_ 45 to M_125, mesocarp samples at 45, 54, 69, 83, 111 and 125 DAFB; F - flower samples.

Additional file 4: Supplementary Fig. 4. Comparison of the O'Henry fruit mesocarp proteome characterized by $2 \mathrm{D}$ gel vs $1 \mathrm{D}$ gel analysis. (a) Mesocarp proteins from mature and ripe O'Henry fruits assessed by 2Dgels had 164 spots that could be quantified [27]. Among these 164 spots, 43 were identified by mass spectrometry analysis and, therefore, were contrasted with the current proteome under analysis. (b) Among these 43 proteins, 16 had accumulation profiles similar to the ones assessed in the current work ("match"), whereas 27 had different patterns ("did not match").

Additional file 5.

Additional file 6 .

Additional file 7.

\section{Abbreviations}

ACHT4: Atypical cysteine/histidine-rich thioredoxin 4ACO - ACC oxidase; ACS: ACC synthase; AP4: Adaptor protein complex 4; APS1: Glucose-1phosphate adenylyltransferase small subunit; BSK: BRASSINOSTEROID-SIGNAL ING KINASE; CXE: Carboxylesterase; DAFB: Days after full bloom; F6P: Fructose 6-phosphate; FAD1: Fatty acid desaturase 1; FERLs: Feronia-like receptor 
kinases; GO: Gene Ontology; MS: Mass spectrometry; PA: Phosphatidic acid; PCA: Principal Component Analysis; PEP: Phosphoenolpyruvate; PG: Polygalacturonase; PLD: Phospholipase D; RAFS: Raffinose synthase; SAM: S-Adenosyl methionine; SBE: 1,4-alpha-glucan-branching enzyme; SOT: Sorbitol transporter; TFs: Transcription factors; TIC: Total ion chromatograms

\section{Acknowledgements}

Doug Whitten from Research Technology Support Facility, Proteomics Core Facility at Michigan State University for advising in proteomics analysis. Dr. Reinaldo Campos-Vargas for providing peach fruit mesocarp samples.

\section{Authors' contributions}

R.N-P. Protein extraction and display, bioinformatics and statistical analysis; C.M., G.B. collaborated on data analysis; A.O., A.M.A. experimental design, provided research opportunity; R.N-P., A.M.A. wrote the manuscript. All authors read and approved the final manuscript.

\section{Funding}

The work was supported by Fondo Nacional de Desarrollo Científico y Tecnológico (Fondecyt, Chile) - Fondecyt Iniciación 11150107 to R.N-P. and Fondecyt Regular 1130197 to A.M.A. Fundings were used for conception and design of the study, proteome and bioinformatic analysis as well as for salary to R.N-P. and G.B. Open Access funding was enabled by Fondecyt Regular 1201010 to A.M.A.

\section{Availability of data and materials}

Supporting material and protein datasets has been deposited to Mass Spectrometry Interactive Virtual Environment (MassIVE) under accession number MSV000086519 or ftp://massive.ucsd.edu/MSV000086519/. Data generated during analysis are included in the manuscript as supplementary files.

\section{Ethics approval and consent to participate}

Not applicable.

\section{Consent for publication}

Not applicable.

\section{Competing interests}

The authors declare that they have no competing interests.

\section{Author details}

'Escuela de Biotecnología, Facultad de Ciencias, Universidad Mayor, Camino La Pirámide, 5750 Huechuraba, Chile. ${ }^{2}$ Université Claude Bernard Lyon 1, 69622 Villeurbanne, France. ${ }^{3}$ Inria Grenoble Rhône-Alpes, 38334 Montbonnot, France. ${ }^{4}$ Centro de Biotecnología Vegetal, Facultad Ciencias Biológicas, Universidad Andrés Bello, República 330, Santiago, Chile. ${ }^{5}$ Center for Genome Regulation, Blanco Encalada, 2085 Santiago, Chile. ${ }^{6}$ Centro de Genómica y Bioinformática, Facultad de Ciencias, Universidad Mayor, Camino La Pirámide,

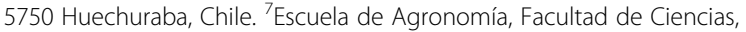
Universidad Mayor, Camino La Pirámide, 5750 Huechuraba, Chile.

\section{Received: 3 April 2020 Accepted: 2 December 2020}

\section{Published online: 06 January 2021}

\section{References}

1. Cao K, Zheng Z, Wang L, Liu X, Zhu G, Fang W, Cheng S, Zeng P, Chen C, Wang X, Xie M, Zhong X, Wang X, Zhao P, Bian C, Zhu Y, Zhang J, Ma G, Chen C, Li Y, Hao F, Li Y, Huang G, Li Y, Li H, Guo J, Xu X, Wang J. Comparative population genomics reveals the domestication history of the peach, Prunus persica, and human influences on perennial fruit crops. Genome Biol. 2014;15(7):415

2. Monti LL, Bustamante CA, Osorio S, Gabilondo J, Borsani J, Lauxmann MA, Maulión E, Valentini G, Budde CO, Fernie AR, Lara MV, Drincovich MF. Metabolic profiling of a range of peach fruit varieties reveals high metabolic diversity and commonalities and differences during ripening. Food Chem. 2016;190:879-88.

3. Verde I, Jenkins J, Dondini L, Micali S, Pagliarani G, Vendramin E, Paris R, Aramini V, Gazza L, Rossini L, Bassi D, Troggio M, Shu S, Grimwood J, Tartarini S, Dettori MT, Schmutz J. The Peach v2.0 release: high-resolution linkage mapping and deep resequencing improve chromosome-scale assembly and contiguity. BMC Genomics. 2017;18(1):225.

4. Aranzana MJ, Decroocq V, Dirlewanger E, Eduardo I, Gao ZS, Gasic K, lezzoni A, Jung S, Peace C, Prieto H, Tao R. Prunus genetics and applications after de novo genome sequencing: achievements and prospects. Horticulture Research. 2019:6(1):1-25.

5. Giovannoni J, Nguyen C, Ampofo B, Zhong S, Fei Z. The epigenome and transcriptional dynamics of fruit ripening. Annu Rev Plant Biol. 2017;68: 61-84.

6. Wu X, Jiang L, Yu M, An X, Ma R, Yu Z. Proteomic analysis of changes in mitochondrial protein expression during peach fruit ripening and senescence. J Proteome. 2016;147:197-211.

7. Gapper NE, McQuinn RP, Giovannoni JJ. Molecular and genetic regulation of fruit ripening. Plant Mol Biol. 2013;82(6):575-91.

8. Sánchez G, Venegas-Calerón M, Salas JJ, Monforte A, Badenes ML, Granell A. An integrative "omics" approach identifies new candidate genes to impact aroma volatiles in peach fruit. BMC Genomics. 2013;14:343.

9. Wang JJ, Liu HR, Gao J, Huang YJ, Zhang B, Chen KS. Two $\omega-3$ FADs are associated with peach fruit volatile formation. Int J Mol Sci. 2016;17(4):464.

10. Zhang L, Li H, Gao L, Qi Y, Fu W, Li X, Zhou X, Gao Q, Gao Z, Jia H. Acyl-CoA oxidase 1 is involved in $\gamma$-decalactone release from peach (Prunus persica) fruit. Plant Cell Rep. 2017;36(6):829-42.

11. Tadiello A, Ziosi V, Negri AS, Noferini M, Fiori G, Busatto N, Espen L, Costa G, Trainotti L. On the role of ethylene, auxin and a GOLVEN-like peptide hormone in the regulation of peach ripening. BMC Plant Biol. 2016;16:44.

12. Wang X, Ding Y, Wang Y, Pan L, Niu L, Lu Z, Cui G, Zeng W, Wang Z. Genes involved in ethylene signal transduction in peach (Prunus persica) and their expression profiles during fruit maturation. Sci Hortic. 2017;224:306-16.

13. Zeng W, Niu L, Wang Z, Wang X, Wang Y, Pan L, Lu Z, Cui G, Weng W, Wang M, Meng X. Application of an antibody chip for screening differentially expressed proteins during peach ripening and identification of a metabolon in the SAM cycle to generate a peach ethylene biosynthesis model. Hortic Res. 2020;7(1):1-4.

14. Trainotti L, Zanin D, Casadoro G. A cell wall-oriented genomic approach reveals a new and unexpected complexity of the softening in peaches. J Exp Bot. 2003;54(389):1821-32.

15. Cao S, Liang M, Shi L, Shao J, Song C, Bian K, Chen W, Yang Z. Accumulation of carotenoids and expression of carotenogenic genes in peach fruit. Food Chem. 2017;214:137-46.

16. Cao K, Ding T, Mao D, Zhu G, Fang W, Chen C, Wang X, Wang L. Transcriptome analysis reveals novel genes involved in anthocyanin biosynthesis in the flesh of peach. Plant Physiol Biochem. 2017;123:94-102.

17. Famiani F, Farinelli D, Moscatello S, Battistelli A, Leegood RC, Walker RP. The contribution of stored malate and citrate to the substrate requirements of metabolism of ripening peach (Prunus persica L. Batsch) flesh is negligible. Implications for the occurrence of phosphoenolpyruvate carboxykinase and gluconeogenesis. Plant Physiol Biochem. 2016;101:33-42.

18. Vimolmangkang $S$, Zheng $H$, Peng $Q$, Jiang $Q$, Wang $H$, Fang $T$, Liao $L$, Wang L, He H, Han Y. Assessment of sugar components and genes involved in the regulation of sucrose accumulation in peach fruit. J Agric Food Chem. 2016;64(35):6723-9.

19. Desnoues E, Génard M, Quilot-Turion B, Baldazzi V. A kinetic model of sugar metabolism in peach fruit reveals a functional hypothesis of a markedly low fructose-to-glucose ratio phenotype. Plant J. 2018;94(4):685-98.

20. Bianchi VJ, Rubio M, Trainotti L, Verde I, Bonghi C, Martínez-Gómez P. Prunus transcription factors: breeding perspectives. Front Plant Sci. 2015;6:443.

21. Pegoraro C, Tadiello A, Girardi CL, Chaves FC, Quecini V, de Oliveira AC, Trainotti L, Rombaldi CV. Transcriptional regulatory networks controlling woolliness in peach in response to preharvest gibberellin application and cold storage. BMC Plant Biol. 2015;15:279.

22. Pons C, Martí C, Forment J, Crisosto CH, Dandekar AM, Granell A. A genetic genomics-expression approach reveals components of the molecular mechanisms beyond the cell wall that underlie peach fruit woolliness due to cold storage. Plant Mol Biol. 2016;92(4-5):483-503.

23. Nilo-Poyanco R, Vizoso P, Sanhueza D, Balic I, Meneses C, Orellana A, Campos-Vargas R. A Prunus persica genome-wide RNA-seq approach uncovers major differences in the transcriptome among chilling injury sensitive and non-sensitive varieties. Physiol Plant. 2019;166(3):772-93.

24. Abdallah C, Dumas-Gaudot E, Renaut J, Sergeant K. Gel-based and gel-free quantitative proteomics approaches at a glance. Int J Plant Genomics. 2012. https://doi.org/10.1155/2012/494572JF. 
25. Gapper NE, Giovannoni JJ, Watkins CB. Understanding development and ripening of fruit crops in an 'omics' era. Hortic Res. 2014;1:14034.

26. Nilo-Poyanco R, Saffie C, Lilley K, Baeza-Yates R, Cambiazo V, Campos-Vargas R, González M, Meisel LA, Retamales J, Silva H, Orellana A. Proteomic analysis of peach fruit mesocarp softening and chilling injury using difference gel electrophoresis (DIGE). BMC Genomics. 2010;11:43.

27. Nilo-Poyanco R, Campos-Vargas R, Orellana A. Assessment of Prunus persica fruit softening using a proteomics approach. J Proteome. 2012;75(5):1618-38.

28. Campos-Vargas R, Becerra O, Baeza-Yates R, Cambiazo V, Gonzalez M, Meisel L, Orellana A, Retamales J, Silva H, Defilippi BG. Seasonal variation in the development of chilling injury in 'O'Henry' peaches. Sci Hortic-Amsterdam. 2006;110(1):79-83.

29. Pan L, Zeng W, Niu L, Lu Z, Liu H, Cui G, Zhu Y, Chu J, Li W, Fang W, Cai Z, Li G, Wang Z. PpYUC11, a strong candidate gene for the stony hard phenotype in peach (Prunus persica L. Batsch), participates in IAA biosynthesis during fruit ripening. J Exp Bot. 2015;66(22):7031-44.

30. Monti LL, Bustamante CA, Budde CO, Gabilondo J, Müller GL, Lara MV, Drincovich MF. Metabolomic and proteomic profiling of spring lady peach fruit with contrasting woolliness phenotype reveals carbon oxidative processes and proteome reconfiguration in chilling-injured fruit. Postharvest Biol Tec. 2019;151:142-51.

31. Guy HR. Amino acid scale: hydrophobicity scale based on free energy of transfer (kcal/mole). Biophys J. 1985;47:61-70.

32. Lü P, Yu S, Zhu N, Chen YR, Zhou B, Pan Y, Tzeng D, Fabi JP, Argyris J, Garcia-Mas J, Ye N, Zhang J, Grierson D, Xiang J, Fei Z, Giovannoni J, Zhong S. Genome encode analyses reveal the basis of convergent evolution of fleshy fruit ripening. Nat Plants. 2018;4(10):784-91.

33. D'Ambrosio C, Arena S, Rocco M, Verrillo F, Novi G, Viscosi V, Marra M, Scaloni A. Proteomic analysis of apricot fruit during ripening. J Proteome. 2013;78:39-57.

34. Bianco L, Lopez L, Scalone AG, Di Carli M, Desiderio A, Benvenuto E, Perrotta G. Strawberry proteome characterization and its regulation during fruit ripening and in different genotypes. J Proteome. 2009;72(4):586-607.

35. Tanou G, Minas IS, Socossa F, Belghazi M, Xanthopoulou A, Ganopoulos I, Madesis P, Fernie A, Molassiotis A. Exploring priming responses involved in peach fruit acclimation to cold stress. Sci Rep. 2017;7:11358.

36. Wu X, Mason AM, Yu M, Ma R, Yu Z. Quantitative proteomic analysis of preand post-harvest peach fruit ripening based on iTRAQ technique. Acta Physiol Plant. 2017;39(8):181.

37. Huan C, Xu Y, An X, Yu M, Ma R, Zheng X. Yu Z iTRAQ-based protein profiling of peach fruit during ripening and senescence under different temperatures. Postharvest Biol Tec. 2019;151:88-97.

38. Jiang L, Kang R, Feng L, Yu Z, Luo H. iTRAQ-based quantitative proteomic analysis of peach fruit (Prunus persica L.) at different ripening and postharvest storage stages. Postharvest Biol Tec. 2020;164:111137.

39. Papavasileiou A, Tanou G, Samaras A, Samiotaki M, Molassiotis A, Karaoglanidis $G$. Proteomic analysis upon peach fruit infection with Monilinia fructicola and M laxa identify responses contributing to brown rot resistance Sci Rep 2020; 10:7807.

40. Asara JM, Christofk HR, Freimark LM, Cantley LC. A label-free quantification method by MS/MS TIC compared to SILAC and spectral counting in a proteomics screen. Proteomics. 2008;8(5):994-9.

41. Lindemann C, Thomanek N, Hundt F, Lerari T, Meyer HE, Wolters D, Marcus K. Strategies in relative and absolute quantitative mass spectrometry based proteomics. Biol Chem. 2017;398(5-6):687-99.

42. Zhao Q, Liu C. Chloroplast Chaperonin: An intricate protein folding machine for photosynthesis. Front Mol Biosci. 2018;4:98.

43. Velasco D, Hough J, Aradhya M, Ross-Ibarra J. Evolutionary Genomics of Peach and Almond Domestication. G3 (Bethesda). 2016:6(12):3985-3993.

44. Qian M, Zhang Y, Yan X, Han M, Li J, Li F, Li F, Zhang D, Zhao C. Identification and expression analysis of polygalacturonase family members during peach fruit softening. Int J Mol Sci. 2016;17(11):1933.

45. Hayama H, Shimada T, Fujii H, Ito A, Kashimura Y. Ethylene-regulation of fruit softening and softening-related genes in peach. J Exp Bot. 2006;57(15): 4071-7.

46. Zhu Y, Zeng W, Wang X, Pan L, Niu L, Lu Z, Cui G, Wang Z. Characterization and transcript profiling of PME and PMEl gene families during peach fruit maturation. J Am Soc Hortic Sci. 2017;142(4):246-59.

47. Trainotti L, Spolaore S, Ferrarese L, Casadoro G. Characterization of ppEG1, a member of a multigene family which encodes endo-beta-1,4-glucanase in peach. Plant Mol Biol. 1997;34(5):791-802.
48. Li XW, Jiang J, Zhang LP, Yu Y, Ye ZW, Wang XM, Zhou JY, Chai ML, Zhang $H Q$, Arús $P$, Jia HJ. Identification of volatile and softening-related genes using digital gene expression profiles in melting peach. Tree Genet Genomes. 2015;11(4):71.

49. Guo S, Song J, Zhang B, Jiang H, Ma R, Yu M. Genome-wide identification and expression analysis of beta-galactosidase family members during fruit softening of peach [Prunus persica (L.) Batsch]. Postharvest Biol Tec. 2018; 136:111-23.

50. Souza F, Alves E, Pio R, Castro E, Reighard G, Freire Al, Mayer NA, Pimentel R. Influence of temperature on the development of peach fruit in a subtropical climate region. Agronomy. 2019;9(1):20.

51. Pei MS, Cao SH, Wu L, Wang GM, Xie ZH, Gu C, Zhang SL. Comparative transcriptome analyses of fruit development among pears, peaches, and strawberries provide new insights into single sigmoid patterns. BMC Plant Biol. 2020;20(1):1-5.

52. Sugimoto-Shirasu K, Roberts K. "Big it up": endoreduplication and cell-size control in plants. Curr Opin Plant Biol. 2003 1;6(6):544-53.

53. Musseau C, Jorly J, Gadin S, Sørensen I, Deborde C, Bernillon S, Mauxion JP, Atienza I, Moing A, Lemaire-Chamley M, Rose JK. The tomato Guanylatebinding protein SIGBP1 enables fruit tissue differentiation by maintaining Endopolyploid cells in a non-proliferative state. Plant Cell. 2020. https://doi. org/10.1105/tpc.20.00245.

54. Wang X, Zeng W, Ding Y, Wang Y, Niu L, Yao JL, Pan L, Lu Z, Cui G, Li G, Wang Z. Peach ethylene response factor PpeERF2 represses the expression of $\mathrm{ABA}$ biosynthesis and cell wall degradation genes during fruit ripening. Plant Sci. 2019;283:116-26.

55. Ruperti B, Bonghi C, Rasori A, Ramina A, Tonutti P. Characterization and expression of two members of the peach 1-aminocyclopropane1-carboxylate oxidase gene family. Physiol Plant. 2001;111(3): 336-44.

56. Trainotti L, Bonghi C, Ziliotto F, Zanin D, Rasori A, Casadoro G, Ramina A, Tonutti P. The use of microarray $\mu \mathrm{PEACH} 1.0$ to investigate transcriptome changes during transition from pre-climacteric to climacteric phase in peach fruit. Plant Sci. 2006;170(3):606-13.

57. Jia M, Du P, Ding N, Zhang Q, Xing S, Wei L, Zhao Y, Mao W, Li J, Li B, Jia W. Two FERONIA-like receptor kinases regulate apple fruit ripening by modulating ethylene production. Front Plant Sci. 2017;8:1406.

58. Ren H, Willige BC, Jaillais Y, Geng S, Park MY, Gray WM, Chory J. BRASSINOSTEROID-SIGNALING KINASE 3, a plasma membrane-associated scaffold protein involved in early brassinosteroid signaling. PLOS Genet. 2019;15(1):e1007904

59. Wei X, Liu F, Chen C, Ma F, Li M. The Malus domestica sugar transporter gene family: identifications based on genome and expression profiling related to the accumulation of fruit sugars. Front Plant Sci. 2014;5:569.

60. Cirilli M, Bassi D, Ciacciulli A. Sugars in peach fruit: a breeding perspective. Hortic Res. 2016;3:15067.

61. Cantín CM, Gogorcena Y, Moreno MÁ. Analysis of phenotypic variation of sugar profile in different peach and nectarine [Prunus persica (L.) Batsch] breeding progenies. J Sci Food Agric. 2009;89(11):1909-17.

62. Teo G, Suzuki Y, Uratsu SL, Lampinen B, Ormonde N, Hu WK, DeJong TM, Dandekar AM. Silencing leaf sorbitol synthesis alters long-distance partitioning and apple fruit quality. Proc Natl Acad Sci. 2006;103(49):18842-7.

63. Yu CY, Cheng HY, Cheng R, Qi KJ, Gu C, Zhang SL. Expression analysis of sorbitol transporters in pear tissues reveals that PbSOT6/20 is associated with sorbitol accumulation in pear fruits. Sci Hortic. 2019;243:595-601.

64. Fan RC, Peng CC, Xu YH, Wang XF, Li Y, Shang Y, Du SY, Zhao R, Zhang XY, Zhang LY, Zhang DP. Apple sucrose transporter SUT1 and sorbitol transporter SOT6 interact with cytochrome b5 to regulate their affinity for substrate sugars. Plant Physiol. 2009;150(4):1880-901.

65. Gao Z, Maurousset L, Lemoine R, Yoo SD, van Nocker S, Loescher W. Cloning, expression, and characterization of sorbitol transporters from developing sour cherry fruit and leaf sink tissues. Plant Physiol. 2003;131(4): 1566-75.

66. Verde I, Abbott AG, Scalabrin S, Jung S, Shu S, Marroni F, Zhebentyayeva T, Dettori MT, Grimwood J, Cattonaro F, Zuccolo A. The high-quality draft genome of peach (Prunus persica) identifies unique patterns of genetic diversity, domestication and genome evolution. Nat Genet. 2013;45(5):487-94.

67. Nuñez C, Dupré G, Mujica K, Melet L, Meisel L, Almeida AM. Thinning alters the expression of the PpeSUT1 and PpeSUT4 sugar transporter genes and the accumulation of translocated sugars in the fruits of an early season peach variety. Plant Growth Regul. 2019;88(3):283-96. 
68. Guizani M, Maatallah S, Dabbou S, Serrano M, Hajlaou H, Helal AN, KilaniJaziri S. Physiological behaviors and fruit quality changes in five peach cultivars during three ripening stages in a semi-arid climate. Acta Physiol Plant. 2019;41(9):154

69. Etienne A, Génard M, Lobit P, Mbeguié-A-Mbéguié D, Bugaud C. What controls fleshy fruit acidity? A review of malate and citrate accumulation in fruit cells. J Exp Bot. 2013;64(6):1451-69.

70. Hebbelmann I, Selinski J, Wehmeyer C, Goss T, Voss I, Mulo P, Kangasjärvi S, Aro EM, Oelze ML, Dietz KJ, Nunes-Nesi A. Multiple strategies to prevent oxidative stress in Arabidopsis plants lacking the malate valve enzyme NADP-malate dehydrogenase. J Exp Bot. 2012;63(3):1445-59.

71. Zheng B, Zhao L, Jiang X, Cherono S, Liu JJ, Ogutu C, Ntini C, Zhang X, Han $Y$. Assessment of organic acid accumulation and its related genes in peach. Food Chem. 2021;334:127567.

72. Jiang $L$, Feng $L$, Zhang F, Luo H, Yu Z. Peach fruit ripening: proteomic comparative analyses of two cultivars with different flesh texture phenotypes at two ripening stages. Sci Hortic. 2020;260:108610.

73. Eliyahu E, Rog I, Inbal D, Danon A. ACHT4-driven oxidation of APS1 attenuates starch synthesis under low light intensity in Arabidopsis plants. Proc Natl Acad Sci U S A. 2015;112(41):12876-81.

74. Zhang B, Shen JY, Wei WW, Xi WP, Xu CJ, Ferguson I, Chen K. Expression of genes associated with aroma formation derived from the fatty acid pathway during peach fruit ripening. J Agric Food Chem. 2010;58(10):6157-65.

75. Cao X, Xie K, Duan W, Zhu Y, Liu M, Chen K, Klee H, Zhang B. Peach Carboxylesterase PpCXE1 is associated with catabolism of volatile esters. J Agric Food Chem. 2019;67(18):5189-96.

76. Goulet C, Mageroy MH, Lam NB, Floystad A, Tieman DM, Klee HJ. Role of an esterase in flavor volatile variation within the tomato clade. Proc Natl Acad Sci. 2012;109(46):19009-14.

77. Schöttler M, Boland W. Biosynthesis of dodecano-4-lactone in ripening fruits: crucial role of an epoxide-hydrolase in enantioselective generation of aroma components of the nectarine (Prunus persica var. nucipersica) and the strawberry (Fragaria ananassa). Helvetica Chimica Acta. 1996;79(5):1488-96.

78. Pirona R, Vecchietti A, Lazzari B, Caprera A, Malinverni R, Consolandi C, Severgnini M, De Bellis G, Chietera G, Rossini L, Pozzi C. Expression profiling of genes involved in the formation of aroma in two peach genotypes. Plant Biol. 2013;15(3):443-51.

79. Sánchez-Sevilla JF, Cruz-Rus E, Valpuesta V, Botella MA, Amaya I. Deciphering gamma-decalactone biosynthesis in strawberry fruit using a combination of genetic mapping, RNA-Seq and eQTL analyses. BMC Genomics. 2014;15:218.

80. Jincy M, Djanaguiraman M, Jeyakumar P, Subramanian KS, Jayasankar S, Paliyath G. Inhibition of phospholipase D enzyme activity through hexanal leads to delayed mango (Mangifera indica L.) fruit ripening through changes in oxidants and antioxidant enzymes activity. Sci Hortic. 2017;218: 316-25

81. Qin C, Wang C, Wang X. Kinetic analysis of Arabidopsis phospholipase D $\delta$ substrate preference and mechanism of activation by $\mathrm{Ca} 2+$ and phosphatidylinositol 4, 5-bisphosphate. J Biol Chem. 2002;277(51):49685-90.

82. Cai H, Han S, Jiang L, Yu M, Ma R, Yu Z. 1-MCP treatment affects peach fruit aroma metabolism as revealed by transcriptomics and metabolite analyses. Food Res Int. 2019;122:573-84.

83. Regon P, Panda P, Kshetrimayum E, Panda SK. Genome-wide comparative analysis of tonoplast intrinsic protein (TIP) genes in plants. Funct Integr Genomics. 2014;14(4):617-29.

84. Chen YH, Khanal BP, Linde M, Debener T, Alkio M, Knoche M. Expression of putative aquaporin genes in sweet cherry is higher in flesh than skin and most are downregulated during development. Sci Hortic. 2019;244:304-14.

85. Garcia VJ, Xu SL, Ravikumar R, Wang W, Elliott L, Gonzalez E, Fesenko M, Altmann M, Brunschweiger B, Falter-Braun P, Moore I. TRIPP is a plantspecific component of the Arabidopsis TRAPPII membrane trafficking complex with important roles in plant development. Plant Cell. 2020;32(7): 2424-43.

86. Rybak K, Steiner A, Synek L, Klaeger S, Kulich I, Facher E, Wanner G, Kuster B, Zarsky V, Persson S, Assaad FF. Plant cytokinesis is orchestrated by the sequential action of the TRAPPII and exocyst tethering complexes. Dev Cell. 2014;29(5):607-20

87. Brummell DA, Dal Cin V, Crisosto CH, Labavitch JM. Cell wall metabolism during maturation, ripening and senescence of peach fruit. J Exp Bot. 2004; 55(405):2029-39.
88. Kalde M, Elliott L, Ravikumar R, Rybak K, Altmann M, Klaeger S, Wiese C, Abele M, Al B, Kalbfuß N, Qi X. Interactions between transport protein particle (TRAPP) complexes and Rab GTP ases in Arabidopsis. Plant J. 2019; 100(2):279-97.

89. Nielsen E. The small GTPase superfamily in plants: A conserved regulatory module with novel functions. Annu Rev Plant Biol. 2020;71:247-72.

90. Pertl-Obermeyer H, Wu XN, Schrodt J, Müdsam C, Obermeyer G, Schulze WX. Identification of cargo for adaptor protein (AP) complexes 3 and 4 by sucrose gradient profiling. Mol Cell Proteomics. 2016;15(9):2877-89.

91. Müdsam C, Wollschläger P, Sauer N, Schneider S. Sorting of Arabidopsis NRAMP3 and NRAMP4 depends on adaptor protein complex AP4 and a dileucine-based motif. Traffic. 2018;19(7):503-21.

92. Di Matteo A, Ruggieri V, Sacco A, Rigano MM, Carriero F, Bolger A, Fernie $A R$, Frusciante L, Barone A. Identification of candidate genes for phenolics accumulation in tomato fruit. Plant Sci. 2013;205:87-96.

93. Xi W, Feng J, Liu Y, Zhang S, Zhao G. The R2R3-MYB transcription factor PaMYB10 is involved in anthocyanin biosynthesis in apricots and determines red blushed skin. BMC Plant Biol. 2019;19(1):287.

94. Zhang Q, Feng C, Li W, Qu Z, Zeng M, Xi W. Transcriptional regulatory networks controlling taste and aroma quality of apricot (Prunus armeniaca $\mathrm{L}$. ) fruit during ripening. BMC Genomics. 2019;20(1):1-5.

95. Ríos P, Argyris J, Vegas J, Leida C, Kenigswald M, Tzuri G, Troadec C, Bendahmane A, Katzir N, Picó B, Monforte AJ. ETHQV 6.3 is involved in melon climacteric fruit ripening and is encoded by a NAC domain transcription factor. Plant J. 2017;91(4):671-83.

96. Liang SM, Chen SC, Liu ZL, Shan W, Chen JY, Lu WJ, Lakshmanan P, Kuang JF. MabZIP74 interacts with MaMAPK11-3 to regulate the transcription of MaACO1/4 during banana fruit ripening. Postharvest Biol Tec. 2020;169: 111293.

97. Song CB, Shan W, Kuang JF, Chen JY, Lu WJ. The basic helix-loop-helix transcription factor MabHLH7 positively regulates cell wall-modifying-related genes during banana fruit ripening. Postharvest Biol Tec. 2020;161:111068.

98. Zhu M, Chen G, Zhou S, Tu Y, Wang Y, Dong T, Hu Z. A new tomato NAC (N AM/A TAF1/2/C UC2) transcription factor, SINAC4, functions as a positive regulator of fruit ripening and carotenoid accumulation. Plant Cell Physiol. 2014;55(1):119-35.

99. Mou W, Li D, Luo Z, Li L, Mao L, Ying T. SIAREB1 transcriptional activation of NOR is involved in abscisic acid-modulated ethylene biosynthesis during tomato fruit ripening. Plant Sci. 2018;276:239-49.

100. Fu CC, Han YC, Fan ZQ, Chen JY, Chen WX, Lu WJ, Kuang JF. The papaya transcription factor CPNAC1 modulates carotenoid biosynthesis through activating phytoene desaturase genes CpPDS2/4 during fruit ripening. J Agric Food Chem. 2016;64(27):5454-63.

101. Fu C, Chen H, Gao H, Lu Y, Han C, Han Y. Two papaya MYB proteins function in fruit ripening through regulating some genes involved in cell wall degradation and carotenoid biosynthesis. J Sci Food Agric. 2020.

102. Zhang T, Li W, Xie R, Xu L, Zhou Y, Li H, Yuan C, Zheng X, Xiao L, Liu K. CPARF2 and CPEIL1 interact to mediate auxin-ethylene interaction and regulate fruit ripening in papaya. Plant J. 2020. https://doi.org/10.1111/tpj. 14803.

103. Li J, Li F, Qian M, Han M, Liu H, Zhang D, Ma J, Zhao C. Characteristics and regulatory pathway of the PrupeSEP1 SEPALLATA gene during ripening and softening in peach fruits. Plant Sci. 2017;257:63-73.

104. Gu C, Guo ZH, Cheng HY, Zhou YH, Qi KJ, Wang GM, Zhang SL. A HD-ZIP ॥ HOMEBOX transcription factor, PpHB. G7, mediates ethylene biosynthesis during fruit ripening in peach. Plant Sci. 2019;278:12-9.

105. Zhou H, Zhao L, Yang Q, Amar MH, Ogutu C, Peng Q, Liao L, Zhang J, Han $Y$. Identification of EIL and ERF genes related to fruit ripening in peach. Int J Mol Sci. 2020;21(8):2846.

106. Diao D, Hu X, Guan D, Wang W, Yang H, Liu Y. Genome-wide identification of the ARF (auxin response factor) gene family in peach and their expression analysis. Mol Biol Rep. 2020.

107. Gao Y, Wei W, Fan Z, Zhao X, Zhang Y, Jing Y, Zhu B, Zhu H, Shan W, Chen $J$, Grierson D. Re-evaluation of the nor mutation and the role of the NACNOR transcription factor in tomato fruit ripening. J Exp Bot. 2020;71(12): 3560-74.

108. Tranbarger TJ, Fooyontphanich K, Roongsattham P, Pizot M, Collin M, Jantasuriyarat C, Suraninpong P, Tragoonrung S, Dussert S, Verdeil JL, Morcillo F. Transcriptome analysis of cell wall and NAC domain transcription factor genes during Elaeis quineensis fruit ripening: evidence for widespread conservation within monocot and eudicot lineages. Front Plant Sci. 2017;8:603. 
109. Wang C, Dong Y, Zhu L, Wang L, Yan L, Wang M, Zhu Q, Nan X, Li Y, Li J. Comparative transcriptome analysis of two contrasting wolfberry genotypes during fruit development and ripening and characterization of the LrMYB1 transcription factor that regulates flavonoid biosynthesis. BMC Genomics. 2020;21:1-8.

110. Meng X, Yang D, Li X, Zhao S, Sui N, Meng Q. Physiological changes in fruit ripening caused by overexpression of tomato SIAN2, an R2R3-MYB factor. Plant Physiol Biochem. 2015;89:24-30.

111. Cheng Y, Liu L, Yuan C, Guan J. Molecular characterization of ethyleneregulated anthocyanin biosynthesis in plums during fruit ripening. Plant $\mathrm{Mol}$ Biol Rep. 2016;34(4):777-85

112. Allan AC, Espley RV. MYBs drive novel consumer traits in fruits and vegetables. Trends Plant Sci. 2018;23(8):693-705.

113. Fujisawa M, Nakano T, Shima Y, Ito Y. A large-scale identification of direct targets of the tomato MADS box transcription factor RIPENING INHIBITOR reveals the regulation of fruit ripening. Plant Cell. 2013;25(2):371-86.

114. https://www.plabipd.de. Accessed Aug 2020

115. Fang $Y$, Robinson DP, Foster LJ. Quantitative analysis of proteome coverage and recovery rates for upstream fractionation methods in proteomics. J Proteome Res. 2010;9(4):1902-12.

116. Jorrin-Novo JV, Komatsu S, Sanchez-Lucas R, de Francisco LE. Gel electrophoresis-based plant proteomics: past, present, and future. Happy 10th anniversary journal of proteomics! J Proteome. 2019;198:1-10.

117. Buchberger AR, DeLaney K, Johnson J, Li L. Mass spectrometry imaging: a review of emerging advancements and future insights. Anal Chem. 2018; 90(1):240-65.

118. Jorrin-Novo JV. What is new in (plant) proteomics methods and protocols: the 2015-2019 Quinquennium. In plant proteomics 2020 (pp. 1-10). Humana, New York.

119. Liu Z, Ma H, Jung S, Main D, Guo L. Developmental mechanisms of fleshy fruit diversity in Rosaceae. Ann Rev Plant Biol. 2020;71:547-73.

120. Botton A, Rasori A, Ziliotto F, Moing A, Maucourt M, Bernillon S, Deborde C, Petterle A, Varotto S, Bonghi C. The peach HECATE3-like gene FLESHY plays a double role during fruit development. Plant Mol Biol. 2016;91(1-2):97-114.

121. Giné-Bordonaba J, Eduardo I, Arús P, Cantín CM. Biochemical and genetic implications of the slow ripening phenotype in peach fruit. Sci Hortic. 2020; 259:108824.

122. Andrade D, Covarrubias MP, Benedetto G, Pereira EG, Almeida AM. Differential source-sink manipulation affects leaf carbohydrate and photosynthesis of early-and late-harvest nectarine varieties. Theor Exp Plant Phys. 2019;31(2):341-56.

123. Minas IS, Blanco-Cipollone F, Sterle D. Accurate non-destructive prediction of peach fruit internal quality and physiological maturity with a single scan using near infrared spectroscopy. Food Chem. 2020;127626.

124. Abdi N, Holford P, Mcglasson B. Application of two-dimensional gel electrophoresis to detect proteins associated with harvest maturity in stonefruit. Postharvest Biol Tec. 2002;26(1):1-13.

125. Mechin V, Consoli L, Le Guilloux M, Damerval C. An efficient solubilization buffer for plant proteins focused in immobilized pH gradients. PROTEOMICS: International Edition. 2003;3(7):1299-302.

126. Bradford MM. A rapid and sensitive method for the quantitation of microgram quantities of protein utilizing the principle of protein-dye binding. Anal Biochem. 1976:72:248-54.

127. Shevchenko A, Wilm M, Vorm O, Mann M. Mass spectrometric sequencing of proteins silver-stained polyacrylamide gels. Anal Chem. 1996;68(5):850-8.

128. Goodstein DM, Shu S, Howson R, Neupane R, Hayes RD, Fazo J, Mitros T, Dirks W, Hellsten U, Putnam N, Rokhsar DS. Phytozome: a comparative platform for green plant genomics. Nucleic Acids Res. 2012;40:D1178-86.

129. van den Berg RA, Hoefsloot HC, Westerhuis JA, Smilde AK, van der Werf MJ. Centering, scaling, and transformations: improving the biological information content of metabolomics data. BMC Genomics. 2006;7:142.

130. Taverner T, Karpievitch YV, Polpitiya AD, Brown JN, Dabney AR, Anderson GA, Smith RD. DanteR: an extensible R-based tool for quantitative analysis of -omics data. Bioinformatics. 2012;28(18):2404-6.

131. Osorio D, Rondón-Villarrea P, Torres R. Peptides: a package for data mining of antimicrobial peptides. R Journal. 2015;7(1):4-14.

132. Supek F, Bošnjak M, Škunca N, Šmuc T. REVIGO summarizes and visualizes long lists of gene ontology terms. PLoS One. 2011;6(7):e21800.

133. Kuznetsova I, Lugmayr A, Siira SJ, Rackham O, Filipovska A. CirGO: an alternative circular way of visualising gene ontology terms. BMC Bioinformatics. 2019;20(1):84.
134. Ryu JY, Kim HU, Lee SY. Deep learning enables high-quality and highthroughput prediction of enzyme commission numbers. Proc Natl Acad Sci U S A. 2019;116(28):13996-4001.

135. Karp PD, Latendresse $M$, Paley SM, Krummenacker M, Ong QD, Billington $R$, Kothari A, Weaver D, Lee T, Subhraveti P, Spaulding A. Pathway tools version 19.0 update: software for pathway/genome informatics and systems biology. Brief Bioinform. 2016;17(5):877-90.

136. Barrett T, Wilhite SE, Ledoux P, Evangelista C, Kim IF, Tomashevsky M, Marshall KA, Phillippy KH, Sherman PM, Holko M, Yefanov A. NCBI GEO: archive for functional genomics data sets-update. Nucleic Acids Res. 2012; 41(D1):D991-5.

137. Barter RL, Yu B. Superheat: An R package for creating beautiful and extendable heatmaps for visualizing complex data. J Comput Graph Stat. 2018;27(4):910-22.

138. Ritchie ME, Phipson B, Wu DI, Hu Y, Law CW, Shi W, Smyth GK. limma powers differential expression analyses for RNA-sequencing and microarray studies. Nucleic Acids Research. 2015;43(7):e47.

139. Jin J, Tian F, Yang DC, Meng YQ, Kong L, Luo J, Gao G. PlantTFDB 4.0: toward a central hub for transcription factors and regulatory interactions in plants. Nucleic Acids Res. 2017:45(D1):D1040-5.

140. Van Bel M, Diels T, Vancaester E, Kreft L, Botzki A, Van de Peer Y, Coppens F, Vandepoele K. PLAZA 4.0: an integrative resource for functional, evolutionary and comparative plant genomics. Nucleic Acids Res. 2018; 46(D1):D1190-6.

\section{Publisher's Note}

Springer Nature remains neutral with regard to jurisdictional claims in published maps and institutional affiliations.
Ready to submit your research? Choose BMC and benefit from:

- fast, convenient online submission

- thorough peer review by experienced researchers in your field

- rapid publication on acceptance

- support for research data, including large and complex data types

- gold Open Access which fosters wider collaboration and increased citations

- maximum visibility for your research: over $100 \mathrm{M}$ website views per year

At $\mathrm{BMC}$, research is always in progress.

Learn more biomedcentral.com/submissions 